\title{
Microtubule-associated proteins promote microtubule generation in the absence of $\gamma$-tubulin in human colon cancer cells
}

\author{
Kenta Tsuchiya $^{1}$ and Gohta Goshima ${ }^{1,2 *}$ \\ ${ }^{1}$ Division of Biological Science, Graduate School of Science, Nagoya University, Furo- \\ cho, Chikusa-ku, Nagoya, Aichi 464-8602, Japan \\ ${ }^{2}$ Sugashima Marine Biological Laboratory, Graduate School of Science, Nagoya \\ University, Sugashima, 429-63, Toba 517-0004, Japan \\ ${ }^{*}$ Correspondence should be addressed to goshima@bio.nagoya-u.ac.jp \\ Phone: +81 599-34-2216
}

\begin{abstract}
$\gamma$-Tubulin complex acts as the predominant microtubule (MT) nucleator that initiates MT formation and is therefore an essential factor for cell proliferation. Nonetheless, cellular MTs are formed after experimental depletion of the $\gamma$-tubulin complex, suggesting that cells possess other factors that drive MT nucleation. Here, by combining gene knockout, auxin-inducible degron, RNA interference, MT depolymerisation/regrowth assay, and live microscopy, we identified four microtubule-associated proteins (MAPs), ch-TOG, CLASP1, CAMSAPs, and TPX2, which are involved in $\gamma$-tubulin-independent MT generation in human colon cancer cells. In the mitotic MT regrowth assay, nucleated MTs organised non-centriolar MT organising centres (ncMTOCs) in the absence of $\gamma$-tubulin. Depletion of CLASP1 or TPX2 substantially delayed ncMTOC formation, suggesting that they promote MT nucleation in the absence of $\gamma$-tubulin. In contrast, depletion of CAMSAPs or ch-TOG did not affect the timing of ncMTOC appearance. CLASP1 also accelerates $\gamma$-tubulin-independent MT regrowth during interphase. Thus, MT generation can be promoted by MAPs without the $\gamma$-tubulin template.
\end{abstract}

\section{Introduction}

Microtubules (MTs) are cytoskeletal filaments essential for various cellular activities, such as chromosome segregation, cell division, cell polarisation, and organelle transport. MTs are formed via the polymerisation of $\alpha$ - and $\beta$-tubulin heterodimers. MT formation begins with MT nucleation, where tubulin dimers assemble into oligomers and form a 'critical nucleus' (Roostalu and Surrey, 2017). The MT nucleus then recruits more tubulin dimers, leading to persistent MT polymerisation or growth, until the MTs pause or start depolymerisation. This entire reaction can take place solely with a high concentration of pure tubulin with GTP in the test tube. However, the initial nucleation step is assumed to be a challenging process in vivo, where the tubulin amount is limited and some factors destabilise MTs. The discovery of another class of tubulin, $\gamma$-tubulin, and its associated subunits called GCPs, provided key insights into how eukaryotic cells efficiently nucleate MTs (Liu et al., 2021; Oakley and Oakley, 1989; Tovey and Conduit, 2018). The ringshaped $\gamma$-tubulin complex ( $\gamma$-TuRC) serves as the structural template for the initial tubulin assembly, thereby accelerating the initial lag phase (Zheng et al., 1995). However, the $\gamma$ - 
TuRC alone is not an efficient MT nucleator, and efficient nucleation requires association with other proteins, such as CDK5RAP2, XMAP215/ch-TOG, TPX2, and augmin (Alfaro-Aco et al., 2020; Choi et al., 2010; Consolati et al., 2020; Flor-Parra et al., 2018; Tariq et al., 2020; Thawani et al., 2018). Some of these activators likely alter the conformation of $\gamma$-TuRC to better fit the ends of MT protofilaments (Consolati et al., 2020; Liu et al., 2020; Wieczorek et al., 2020), whereas others cooperate with $\gamma$-TuRC (Consolati et al., 2020; Flor-Parra et al., 2018; King et al., 2020; Thawani et al., 2018). It is now well established that $\gamma$-TuRC, with its activators, is the dominant MT nucleator in most eukaryotic cell types. However, there remains another enigma regarding $\gamma$-TuRC: cellular MTs are still present after $\gamma$-TuRC depletion or perturbation in every system examined to date, including inhibitor treatment and RNA interference (RNAi) in animals and plants (Chinen et al., 2015; Hannak et al., 2002; Nakaoka et al., 2015; Rogers et al., 2008; Sallee et al., 2018; Wang et al., 2015). For instance, RNAi or tissue-specific degradation system reportedly depleted $>90 \%$ of $\gamma$-TuRC from C. elegans cells, yet MTs were still nucleated from the centrosome in the early emrbyo (Hannak et al., 2002) or acentrosomal MTOCs in intestinal epithelial cells (Sallee et al., 2018).

This phenomenon is possibly due to the sufficient amount of residual $\gamma$-TuRC for a certain degree of MT nucleation. This is not an ignorable caveat. Recent reconstitution studies indicate that a partial complex with eight $\gamma$-tubulin subunits is as potent as the full complex of $14 \gamma$-tubulin in facilitating MT nucleation (Wieczorek et al., 2021). To establish the dispensability of $\gamma$-tubulin, the best approach is to genetically delete $\gamma$ tubulin. However, because $\gamma$-tubulin is an essential gene for mitosis in every cell type, it has been impossible to establish a stable cell line in which $\gamma$-tubulin genes are deleted. In one study, CRISPR-based genome editing transiently created $\gamma$-tubulin gene-deleted cells, which failed to assemble functional spindles (McKinley and Cheeseman, 2017); however, the amount of residual $\gamma$-tubulin proteins in each cell was unclear. Another possible explanation for the remaining MTs after $\gamma$-tubulin depletion or inhibition is that cells have other factors that can nucleate MTs independent of $\gamma$-tubulin. Indeed, several MTassociated proteins (MAPs), whose major activity may not be considered MT nucleation, can promote MT nucleation in vitro when mixed with tubulin (Brunet et al., 2004; Imasaki et al., 2021; King et al., 2020; Roostalu et al., 2015; Slep and Vale, 2007). They are candidates for $\gamma$-tubulin-independent nucleators in cells.

The aim of this study was to identify the proteins required for $\gamma$-tubulin-independent MT nucleation in a single cell type in humans. We first verified that MTs can be nucleated in cells with undetectable levels of $\gamma$-tubulin and then searched for the MAPs required for MT generation under these conditions. Our study suggests that multiple factors, including CLASP1 and TPX2, are cellular MT nucleators that are normally masked by the dominant $\gamma$-TuRC machinery.

\section{Results}

\section{MT formation with undetectable levels of $\boldsymbol{\gamma}$-tubulin}

Most previous studies utilised population assays to assess the contribution of $\gamma$ tubulin to MT nucleation, which did not correlate the reduction level of $\gamma$-tubulin with MT nucleation potential at the single-cell level. In this study, one of the two $\gamma$-tubulin genes in humans (TUBG2) was knocked out, and the other TubG1 protein was tagged 

allowed acute degradation of the tagged protein via the proteasome. We selected the human HCT116 cell line for this study, which is a stable diploid line derived from colon cancer (Brattain et al., 1981). This cell line is amenable to CRISPR/Cas9-based genome editing and RNAi, and its mitosis has been studied in our laboratory (Okumura et al., 2018; Tsuchiya et al., 2021; Tungadi et al., 2017).

Prior to studying MT nucleation, we performed a basic characterisation of this cell line. First, TubG1-mAID-mClover was localised to the centrosome and spindle MTs, consistent with immunostaining in various human cell lines (Luders et al., 2006) (Fig. 1D, Movie 1). Second, the mitotic progression ( $31 \pm 8 \mathrm{~min}[ \pm \mathrm{SD}], \mathrm{n}=49$; Fig. 1E) was comparable to that in the control cell line ( $34 \pm 8$ min; Tsuchiya et al., 2021). Finally, we performed sucrose gradient centrifugation, followed by immunoblotting (Fig. 1B, C). The results indicated that TubG1-mAID-mClover was assembled into the large $\gamma$-TuRC complex. Given the addition of 14 copies of mAID-mClover tag (each $\sim 30 \mathrm{kD}$ ), it was reasonable that the peak of the tagged protein was shifted by one lane to a larger fraction than endogenous TubG1. A slightly smaller complex was also detected for tagged TubG1 (lane 10 in Fig. 1C); this may be because the tag partially prevents incorporation into the complete $\gamma$-TuRC. Nevertheless, the result is consistent with the observation that endogenous TubG1 can be completely replaced with TubG1-mAID-mClover in this human cell line.

Upon indole acetic acid (IAA) treatment, cells showed different levels of mClover signals (as observed using a spinning-disc confocal microscope) owing to varying degradation levels in interphase and mitosis (Fig. 2A-C). This was confirmed by the quantification of the mClover signal intensity (Fig. 2D, E). The cells in which we could not detect residual $\gamma$-tubulin signals by manual inspection always returned low signal values after quantification (coloured pink in the graph). However, the opposite was not true; the cells with very low signals in quantification did not always represent $\gamma$-tubulinnull based on manual inspection; they included cells with faint punctate mClover signals at the centrosome, which did not contribute markedly to the total intensity. Therefore, in the subsequent analysis, we manually inspected the acquired images and selected "mClover signals undetectable" cells; these cells were closest to $\gamma$-tubulin null. The neighbouring cells with mClover signals served as internal controls. Regardless of the presence or absence of mClover signals, MTs visualised with SiR-tubulin were present in every cell during interphase (Fig. 2A). Furthermore, the cells assembled tiny spindles in mitosis and could not enter anaphase (Fig. 1D, E, Movie 2). These results support the presence of $\gamma$-tubulin-independent MT nucleation during interphase and mitosis.

\section{MT nucleation in the absence of $\boldsymbol{\gamma}$-tubulin}

To assess MT generation ability without $\gamma$-tubulin in living cells, we performed an MT depolymerisation/regrowth assay, in which MTs were first depolymerised with the MT drug nocodazole, followed by drug washout (Fig. 3A, Movie 3). The experiments were mostly performed at $25^{\circ} \mathrm{C}$, as MTs reappeared too quickly after drug washout at $37^{\circ} \mathrm{C}$; MT nucleation took place prior to image acquisition. For normal HCT116 cells, $25^{\circ} \mathrm{C}$ is a challenging temperature, as evidenced by the fact that bipolar spindle formation requires $>30 \mathrm{~min}$ (Fig. S2A, B). However, this was compensated for in the regrowth assay, as the initial tubulin concentration was higher than that in normal cycling cells due 
140 to complete MT depolymerisation beforehand. In cells that retained TubG1-mClover

141 signals (circled yellow), cytoplasmic MTs were observed 10 min after drug washout, with

142 the centrosome being the most prominent MT organising centre (MTOC) (43 out of 45

143 cells showed cytoplasmic MT network at $10 \mathrm{~min}$ ) (Fig. 3B). In contrast, cytoplasmic MTs

144 were hardly detected until 20-30 min in the absence of $\gamma$-tubulin, with no clear MTOCs

145 (circled red; 33 out of 42 cells showed no cytoplasmic MT networks at $10 \mathrm{~min}$ ).

To further demonstrate that MT nucleation occurs in the absence of $\gamma$-TuRC as the nucleator, we observed the cells undergoing MT regrowth using oblique illumination fluorescence microscopy, which is sensitive enough to detect a single $\gamma$-tubulin complex containing $>10$ fluorescent mClover molecules and an occasional MT nucleation event (Nakaoka et al., 2015). We observed many punctate signals in control cells, each likely representing a cytoplasmic $\gamma$-TuRC near the cell cortex (Fig. 4A, yellow circle). We could not identify a MT nucleating event from the observed $\gamma$-TuRC spots; MT emergence under these conditions represented MT plus ends grown from the other focal plane. This was because MT nucleation predominantly occurred at the centrosome, which could not be localised to the focal plane in this microscopy. In contrast, after degron treatment, some cells hardly showed punctate signals of mClover, despite the presence of MTs (Fig. $4 \mathrm{~B}$, red circle). MTs were generated in the absence of $\gamma$-tubulin (i.e. undetectable levels of mClover signals), albeit more slowly (Fig. 4C). Under these conditions, we occasionally identified MT nucleating events, in which MT punctae diffused in 2D, which is an indicator of nucleation rather than plus-end growth from the off-focal plane (Fig. 4D, arrows). Furthermore, we observed at higher frequency the MT loop formation in which both ends were clearly in the focal plane (Fig. 4B, right, Fig. 4D, bottom right, Movie 4); the diameter of the loop was $0.85 \pm 0.26 \mu \mathrm{m}( \pm \mathrm{SD}, \mathrm{n}=29)$, which resembles what has been observed in an in vitro MT gliding assay (Liu et al., 2011).

To determine whether there is a possible artifactual effect of SiR-tubulin dye on MT nucleation and growth ability, we compared the timing of MT appearance and MT growth rate in the presence or absence of SiR-tubulin. To visualise MTs without SiR-tubulin, we selected and used a cell line in which endogenous ch-TOG was tagged with mCherry (Fig. S1C, S2C, Movie 1). The data indicate that the effect of SiR-tubulin on MT nucleation and growth is mild (Fig. S2D, E).

Taken together, we concluded that $\gamma$-TuRC constitutes the dominant, but not essential, mechanism of MT nucleation in the interphase cytoplasm.

\section{ch-TOG, CLASP1, and CAMSAPs are critical for interphase MT generation in the absence of $\gamma$-tubulin}

To identify the factors responsible for $\gamma$-tubulin-independent nucleation, we conducted an RNAi screen of 11 candidate genes (or gene family) using the $\gamma$-tubulin degron line (Fig. 5A). The MT regrowth assay was carried out, and the cells that retained or lacked $\gamma$-tubulin-mClover signals were analysed. In the screening, we identified "MT 180 regrowth" when one or more MTs were detected within 30 min under a spinning-disc 181 confocal microscope. When $\gamma$-tubulin was present, MTs were observed normally in all 182 RNAi samples. In contrast, we observed that more than half of the $\gamma$-tubulin-degraded 183 cells failed to regrow MTs in $30 \mathrm{~min}$ when ch-TOG, CLASP1, or CAMSAP1/2/3 were 184 depleted by RNAi (Fig. 5B-E). In contrast, depletion of CDK5RAP2 or PCNT had no 185 effect on $\gamma$-tubulin-independent MT generation, although it has been shown to promote 
cytoplasmic nucleation in the presence of $\gamma$-tubulin in other cell types (Choi et al., 2010; Gavilan et al., 2018; Wu et al., 2016).

To confirm and specify the responsible genes, we performed loss-of-function analyses after generating new cell lines (Fig. 6A-C, Movie 3). The critical contribution of ch-TOG (Xenopus XMAP215 orthologue), best known as MT polymerase (Brouhard et al., 2008), was confirmed by degron treatment of the line expressing TubG1-mAIDmClover and ch-TOG-mAID-mCherry (Fig. S1C). When neither signal was observed, MT regrowth was undetectable for $30 \mathrm{~min}$ in $>70 \%$ of the cells (Fig. 6A, D). The requirement of AKAP450 (Gavilan et al., 2018; Rivero et al., 2009; Wu et al., 2016) was excluded from the observation of MT regrowth in their verified knockout (KO) lines (Fig. 6D, S1F, S3A). CLASP proteins are best known as MT stabilisers (Al-Bassam et al., 2010; Moriwaki and Goshima, 2016; Yu et al., 2016) and are also required for Golgi- and $\gamma$-tubulin-dependent MT nucleation in RPE1 cells (Efimov et al., 2007). CLASP1 was crucial for MT regrowth, as revealed by the generation of a CLASP1-mAID-mCherry degron line in the background of $\gamma$-tubulin degron (Fig. 6B, D, S1D). CAMSAP family members have been characterised as minus-end stabilisers (Goodwin and Vale, 2010; Jiang et al., 2014), in which the CAMSAP3 KO line showed normal regrowth of MTs (Fig. S1G, S3B, C). However, when CAMSAP1 or CAMSAP2 was depleted by RNAi in the CAMSAP3 KO line, MT regrowth was not observed in $>25 \%$ of the cells (Fig. $6 \mathrm{C}$, D, S3D-G). Quantification of MT intensity at 30 min supported these findings (Fig. 6E). These results indicate that ch-TOG, CLASP1, and CAMSAPs are involved in MT generation during the interphase of $\gamma$-tubulin-depleted cells.

An identical assay was performed at $37^{\circ} \mathrm{C}$ (Fig. 6F). Even under this more favourable condition for MT nucleation and growth, we observed a significant delay in MT nucleation in the absence of $\gamma$-tubulin. Unlike at $25^{\circ} \mathrm{C}$, MTs were observed within $30 \mathrm{~min}$ in the majority of cells after co-depletion with ch-TOG or CLASP1. Interestingly, however, the first appearance of MT was delayed when CLASP1, but not ch-TOG, was co-depleted with $\gamma$-tubulin (Fig. 6F). These results suggest that CLASP1 is involved in the early stage of MT formation, possibly in the nucleation step, in the absence of $\gamma$ tubulin during interphase.

\section{No accumulation of ch-TOG and CLASP1 at the $\gamma$-tubulin-independent nucleation site}

We investigated the possibility that ch-TOG or CLASP first forms an assembly or seed, from which MT nucleates and regrows in the absence of $\gamma$-tubulin in cells. To this end, the ch-TOG-mCherry or CLASP1-mCherry constructs, which did not have the AID tag, were integrated into the TubG1-mClover-mAID/TubG2-KO line, and oblique illumination fluorescence microscopy was performed after $\gamma$-tubulin degradation. We observed MT nucleation and growth after the drug washout. However, ch-TOG or CLASP1 was undetectable at the emergence of MTs; they were later visible near the other end of MTs (Fig. S4). Considering that the SiR-Tubulin dye stains the MT lattice with a $\sim 10$ s delay after actual MT formation (David et al., 2019), it is unlikely that ch-TOG or CLASP1 was abundantly present at the nucleation site. We concluded that a detectable level of assembly of ch-TOG or CLASP1 at MT minus ends was not involved in $\gamma$ tubulin-independent MT regrowth.

\section{$\gamma$-Tubulin-independent MT nucleation and MTOC formation during prometaphase}


Next, we tested the involvement of $\gamma$-tubulin in mitotic MT nucleation through MT depolymerisation and regrowth assay in prometaphase (Movie 5). MTs were depolymerised by $24 \mathrm{~h}$ nocodazole treatment and $4 \mathrm{~h}$ incubation on ice (Fig. 7A). In control cells with $\gamma$-tubulin, MTs were undetectable, except for one or two spots (Fig. 7B, $0 \mathrm{~min}$ ). These most likely reflected centriole-dependent MTs, as MT foci were colocalised with centrin-2 signals in immunostaining images (Fig. S5A), and the punctate signal was not observed when centriole was depleted by a total of 12 days of incubation with centrinone, a chemical inhibitor of the centriole duplication factor Plk4 (Wong et al., 2015) (Fig. S5B). Upon nocodazole washout and returning the cells to $25^{\circ} \mathrm{C}$, MTs were immediately and predominantly nucleated from the centrosomes (Fig. 7B). In the cells in which $\gamma$-tubulin was undetectable, MTs similarly disappeared from the mitotic cytoplasm, retaining one or two punctate signals at the centriole (Fig. 7C, $0 \mathrm{~min}$ ). Upon nocodazole washout, MT regrowth was observed, albeit more slowly, in the absence of $\gamma$-tubulin signals (Fig. 7C, 20-30 min). Impaired regrowth was consistent with the results of a previous study in which a $\gamma$-TuRC component was depleted in HeLa cells (Luders et al., 2006). Interestingly, in addition to centriolar MTOCs (blue arrow at $6 \mathrm{~m} 30 \mathrm{~s}$ ), noncentriolar MTOCs (ncMTOCs) appeared in HCT116 cells, from which MTs later emanated radially (Fig. 7C, right, green arrows). These MTOCs did not have detectable $\gamma$-tubulin signals, indicating that MTs are nucleated independent of $\gamma$-tubulin or preexisting MTs. We confirmed that SiR-tubulin staining had negligible impact, as ncMTOCs (visualised by TPX2-mCherry) appeared at similar times and numbers with or without SiR-tubulin staining (Fig. S5C-E). Thus, $\gamma$-tubulin is not essential for MT nucleation in prometaphase.

\section{TPX2 and CLASP1 promote mitotic MTOC formation, whereas ch-TOG is critical for mitotic MT growth, in the absence of $\gamma$-tubulin}

ncMTOC is formed through MT nucleation, initial growth, stabilisation, and clustering. We investigated the impact of ch-TOG, CAMSAPs, or CLASP1 depletion on ncMTOC formation in the absence of $\gamma$-tubulin.

First, in the absence of ch-TOG alone, ncMTOCs that were clearly separated from centrioles were observed in $\sim 50 \%$ of the cells, probably because centrosomal MT growth was suppressed and tubulins were available for other MTOC formation (Fig. S5F, I). ncMTOC was also observed in CLASP1 knockdown; however, centrosomal MTOCs were dominant over ncMTOCs in this case (Fig. S5G, I). In both cases, MT regrowth from MTOCs was not suppressed (Fig. S5J).

Next, we conducted a regrowth assay after co-depletion with $\gamma$-tubulin. MT depolymerisation removed most MTs, except one or two punctate centriolar signals, similar to control or single $\gamma$-tubulin-depleted cells (Fig. 7D, E, 0 min). In C. elegans, codepletion of $\gamma$-tubulin and the ch-TOG orthologue does not result in additional loss of MT regrowth in mitotic cells (Hannak et al., 2002). However, when $\gamma$-tubulin and ch-TOG were co-depleted, mitotic MT formation was severely suppressed, consistent with the results of the interphase (Fig. 7D). Interestingly, the initial ncMTOC formation was not substantially affected, indicating that MT nucleation occurred, but the subsequent growth was impaired (Fig. 7D, green arrows, 7G). Similarly, depletion of CAMSAPs did not affect the timing of ncMTOC formation (Fig. 7G). In contrast, after depletion of CLASP1, the appearance of ncMTOCs was dramatically delayed (Fig. 7E, G). These results suggest 
that ch-TOG is essential for MT growth, but not the initial nucleation step, whereas CLASP1 contributes to ncMTOC formation in the absence of $\gamma$-tubulin.

TPX2 plays a role in non-centrosomal MT formation during mitosis in multiple cell lines (Gruss et al., 2002). In the MT regrowth assay using LLC-PK1 and HeLa cells, TPX2 was found to be responsible for non-centriolar MT formation in the presence of $\gamma$ tubulin (Cavazza et al., 2016; Katayama et al., 2008; Tulu et al., 2006). We reasoned that this protein might also contribute to ncMTOC formation in the absence of $\gamma$-tubulin. We first selected the degron line (Fig. S1E) and performed the mitotic MT depolymerisation/regrowth assay in the presence of $\gamma$-tubulin. Similar to the ch-TOG degron, ncMTOCs were observed in $\sim 50 \%$ of the cells and MTs regrew from the MTOCs (Fig. S5H-J). This is somewhat different from what has been observed in other studies using different cell lines; in our HCT116 cells, TPX2 was dispensable for ncMTOC formation. To test the contribution of TPX2 in the absence of $\gamma$-tubulin, we selected a double-degron line of TPX2 and $\gamma$-tubulin, and furthermore, combined TPX2 RNAi with $\gamma$-tubulin single or CLASP $1 / \gamma$-tubulin double degrons. We observed a delay in the appearance of ncMTOCs in either case, indicating that TPX2 promotes ncMTOC formation (Fig. 7F, G). However, ncMTOCs were eventually formed in $>50 \%$ of the cells in either sample, suggesting that other unknown factors might also nucleate MTs in the absence of $\gamma$-tubulin during mitosis.

\section{Roles of Aurora and PIk1 kinases}

Three mitotic kinases have been implicated in mitotic MT generation in previous studies: Plk1/Polo (Cavazza et al., 2016) and Aurora A at the centrosome (Katayama et al., 2008; Magnaghi-Jaulin et al., 2019), and Aurora B in chromosome-proximal regions independent of the centrosome (Carmena et al., 2012). In C. elegans, centrosomal MT generation was additively suppressed by depleting $\gamma$-tubulin and Aurora A (Motegi et al., 2006). We tested the contribution of these kinases to $\gamma$-tubulin-independent MT regrowth in prometaphase by preventing their kinase activity with specific inhibitors in $\gamma$-tubulindepleted cells (Fig. 8A).

When the Plk1 inhibitor BI2536 was supplied, ncMTOC formed at normal timing, similar to the control $\gamma$-tubulin single-depleted cells (Fig. 8B, C, F). In contrast, the inhibition of Aurora B inhibitor by ZM447439 or Aurora A kinase by alisertib delayed ncMTOC formation in the absence of $\gamma$-tubulin (Fig. 8D-F). The effect of Aurora B was reproduced by RNAi knockdown of Aurora B. Aurora A and B may be partly involved in non-centriolar MT nucleation in the absence of $\gamma$-tubulin.

\section{Discussion}

\section{MT nucleation in the absence of $\gamma$-tubulin}

The $\gamma$-TuRC is the dominant and arguably the only established cellular MT nucleator in a wide variety of cells. However, experimental perturbation of $\gamma$-TuRC in various cell types has never led to a complete loss of cellular MTs. Using a single cell-based assay that monitors both MTs and endogenous $\gamma$-tubulin, we unambiguously demonstrated that MTs could be nucleated in the absence of $\gamma$-TuRC in human colon cancer cells.

Our functional analysis suggested a possible involvement of MAPs in nucleation. The mitotic MT regrowth assay provided valuable information about non- $\gamma$-tubulin MT nucleators, as ncMTOC was visible in almost all cells when $\gamma$-tubulin was depleted. The 
data indicated that TPX2 and CLASP1 contribute to MTOC formation. In Xenopus egg extracts and by sophisticated in vitro reconstitution, TPX2 was shown to activate augminand $\gamma$-tubulin-dependent branching nucleation (Alfaro-Aco et al., 2020) and promote template-based nucleation (Wieczorek et al., 2015). Our data suggest that TPX2 not only stimulates the $\gamma$-tubulin-dependent process but also potentiates template-free MT nucleation independent of $\gamma$-tubulin in the cell. This is consistent with the finding that recombinant TPX2 can promote MT nucleation in vitro (Brunet et al., 2004; Gruss et al., 2002; Roostalu et al., 2015). From in vitro studies, CLASP1 is best known as a MT stabiliser acting on the MT plus ends and the lattice; it inhibits MT catastrophe and promotes rescue and pausing (Al-Bassam et al., 2010; Moriwaki and Goshima, 2016; Yu et al., 2016). In mitosis, the kinetochore function of CLASP1 has been extensively analysed; however, to our knowledge, the MT nucleation functions have not been extensively discussed (Logarinho et al., 2012; Maffini et al., 2009). CLASPs are known to promote Golgi-mediated MT nucleation during the interphase (Efimov et al., 2007). This function involves AKAP450 and $\gamma$-tubulin and is therefore considered to promote $\gamma$ tubulin-dependent nucleation (Efimov et al., 2007; Gavilan et al., 2018; Rivero et al., 2009; Wu et al., 2016). It is possible that CLASP1 binds to tubulins and MTs, contributing to the formation of the critical nucleus independent of $\gamma$-tubulin. However, because MTOC formation requires not only MT nucleation but also initial growth, stabilisation, and clustering, it cannot be ruled out that TPX2 and CLASP1 regulate the latter three processes.

$\gamma$-Tubulin-independent ncMTOC formation was observed in the absence of ch-TOG or CAMSAPs during prometaphase, suggesting that they are not essential for mitotic MT nucleation. MT growth from these ncMTOCs was also observed frequently in the absence of CAMSAPs. In contrast, MT growth from both centriolar and ncMTOCs was inhibited in the absence of ch-TOG and $\gamma$-tubulin. We interpret that ch-TOG is dispensable for ncMT nucleation, at least in the presence of CLASP1 and TPX2, but is critical for MT polymerisation, which is consistent with the established role of ch-TOG as the MT polymerase. Regarding centriolar MTOCs, an intriguing possibility is that ch-TOG catalyses centriole-based MT nucleation, independent of $\gamma$-tubulin. This is consistent with the proposal on C. elegans centrosomes, where the ch-TOG homologue is recruited and concentrates tubulin for nucleation (Woodruff et al., 2017). However, we cannot exclude the possibility that ch-TOG catalyses plus-end polymerisation from nocodazole-resistant MTs at the centriole.

ch-TOG, CAMSAPs, and CLASP1 were important during $\gamma$-tubulin-independent MT generation in the interphase. Interestingly, the assay conducted at $37{ }^{\circ} \mathrm{C}$ distinguished the phenotype of ch-TOG and CLASP1, which is a favourable condition for tubulin to nucleate and polymerise MTs; MT appearance was delayed specifically in the absence of CLASP1, consistent with the mitosis results. Thus, CLASP1 might be considered involved in the nucleation step, whereas ch-TOG is more critical in MT polymerisation in this cell line. The specific role of CAMSAPs remains unclear, as it is required for MT minus-end stabilisation (Jiang et al., 2014) and might also drive nucleation (Imasaki et al., 2021). In C. elegans, the CAMSAP homolog promotes the assembly of noncentrosomal MT arrays in parallel with $\gamma$-tubulin (Wang et al., 2015).

Are there other factors redundant with CLASP1 and TPX2 for nucleation? Our protein-depletion experiments did not provide all-or-none results. Most notably, we still observed ncMTOCs in $\sim 30 \%$ of the cells after the depletion of $\gamma$-tubulin, CLASP1, and 
TPX2. This might reflect the incomplete depletion of target proteins by AID and RNAi. Alternatively, other MT nucleation factors may also exist. In any case, our data indicate that MT nucleation can be promoted by multiple MAPs in human cells: CLASP1 and TPX2 at the minimum and possibly more.

The mechanism by which CLASP1 or TPX2 promotes nucleation at the molecular level remains unclear. Our imaging suggests that CLASP1 does not form clusters large enough to be visualised by oblique illumination fluorescence microscopy. Thus, the mechanism would be fundamentally different from $\gamma$-tubulin-mediated nucleation, where the ring arrangement of $13 \gamma$-tubulin molecules drives nucleation. These MAPs may enhance the longitudinal and lateral contact between tubulins (Roostalu and Surrey, 2017). Regarding TPX2, phase-separated condensates might act as the tubulin concentrator and thereby the MT nucleator (King and Petry, 2020). Furthermore, an interesting in vitro study has been published recently, in which the critical nucleus was visualised by electron microscopy (Ayukawa et al., 2021). In their model, the nucleus was characterised by straight tubulin oligomers, which are different from curved tubulin dimers in solution. Provided that this model is correct, TPX2 and CLASP might be considered to convert the curved structure to straight via binding. This is a testable hypothesis in vitro.

\section{Does $\boldsymbol{\gamma}$-tubulin-independent nucleation take place in the presence of $\boldsymbol{\gamma}$-tubulin?}

$\gamma$-Tubulin-dependent nucleation at the centrosome is predominant in the HCT116 cell line, and therefore, this study could not determine whether $\gamma$-tubulin-independent nucleation occurs in normal HCT116 cells. However, a few reports, besides that of a simple mutant analysis, show that the $\gamma$-tubulin-independent mechanism is operating and perhaps important in MT generation in other cell types (Roostalu and Surrey, 2017). One system is the protonemal tissue of the moss Physcomitrium patens in which oblique illumination fluorescence microscopy was applied, and the $\gamma$-tubulin complex and MTs could be simultaneously observed (Nakaoka et al., 2015). While 90\% of the nucleating MTs had $\gamma$-tubulin signals at the minus ends, no signals were identified in the other $10 \%$ of wildtype cells. The stability of these MTs was explained by the identification of the plantspecific minus-end binding and stabilising protein Spiral2 (Leong et al., 2018). Another notable system is the non-centrosomal fat body cell in Drosophila, where $\gamma$-tubulin is dispensable for perinuclear MTOC formation, despite being localised at the perinuclear region with the activators (Zheng et al., 2020). In these cells, MTs are generated by CAMSAP and ninein, which recruit ch-TOG. These MTs play critical roles in nuclear positioning. However, single MT or minus ends cannot be specifically visualised in live in this system; it is possible that $\gamma$-tubulin also contributes to MT nucleation under normal conditions. Finally, in the electron tomography of the metaphase spindle, MT ends associated with $\gamma$-TuRC (ends are closed) and without $\gamma$-TuRC (ends are open) were detected (Kamasaki et al., 2013; O'Toole et al., 2003). The open ends represent either plus ends of MTs or the minus ends of MTs nucleated independent of $\gamma$-tubulin. Taken together, it can be assumed that the $\gamma$-tubulin-independent mechanism operates and plays a role in the activity of at least certain animal and plant cell types.

\section{Materials and methods}

\section{Plasmid, cell culture, and cell line selection}


419 Plasmids for CRISPR/Cas9-mediated genome editing and auxin-inducible degron were

420 constructed using standard protocols (Natsume et al., 2016; Okumura et al., 2018). The

421 plasmids and sgRNA sequences used in this study are listed in Tables S1 and S2,

422 respectively. In the normal passage, the HCT116 cell line possessing DOX-inducible tet-

423 OsTIR1 was cultured at $37^{\circ} \mathrm{C}$ with McCoy's 5A medium (Gibco) supplemented with $10 \%$

424 serum and 1\% antibiotics (Natsume et al., 2016). Knock-in and knockout lines were

425 generated by CRISPR/Cas9 genome editing essentially as previously described

426 (Okumura et al., 2018). CRISPR/Cas9 and donor plasmids were co-transfected into the

427 cell lines using Effectene (Qiagen, Venlo, Netherlands). For drug selection, $1 \mu \mathrm{g} / \mathrm{mL}$

428 puromycin (Wako Pure Chemical Industries, Osaka, Japan), $800 \mu \mathrm{g} / \mathrm{mL}$ G418 (Roche,

429 Basel, Switzerland), $200 \mu \mathrm{g} / \mathrm{mL}$ hygromycin B (Wako Pure Chemical Industries), and 8

$430 \mu \mathrm{g} / \mathrm{mL}$ blasticidin S hydrochloride (Funakoshi Biotech, Tokyo, Japan) were used.

431 Selection medium was replaced with fresh selection medium 4-5 d after starting selection.

432 After 10-14 d, colonies grown on a $10 \mathrm{~cm}$ culture dish were washed once with PBS,

433 picked up with a pipette tip under a microscope (EVOS XL, Thermo Fisher Scientific,

434 Waltham, MA) located on a clean bench, and subsequently transferred to a 96-well plate

435 containing $50 \mu \mathrm{L}$ of trypsin-EDTA. After a few minutes, the trypsinized cells were

436 transferred to a 24 -well plate containing $500 \mu \mathrm{L}$ of the selection medium, and then further

437 transferred to a 96 -well plate $(200 \mu \mathrm{L}$ per well) for the preparation of genomic DNA. For

438 the preparation of genomic DNA, cells in the 96-well plate were washed once with PBS

439 and lysed by $90 \mu \mathrm{L}$ of $50 \mathrm{mM} \mathrm{NaOH}$. After boiling for $10 \mathrm{~min}$, the solution was

440 equilibrated by $10 \mu \mathrm{L}$ of $100 \mathrm{mM}$ Tris- $\mathrm{HCl}$ ( $\mathrm{pH} 9.0$ ). To confirm the genomic insertion,

441 PCR was performed using 1-2 $\mu \mathrm{L}$ of the genomic DNA solution and Tks Gflex DNA

442 polymerase (Takara Bio). The primers are listed in Table S3. For the TubG1-KO/TubG2-

443 mClover-mAID line, $\gamma$-tubulin and $\alpha$-tubulin were immunoblotted with monoclonal

444 antibodies GTU88 (Sigma, 1:10,000) and DM1A (Sigma, 1:2,000), respectively, and the

445 lack of untagged $\gamma$-tubulin protein was confirmed. Proper tagging to ch-TOG, CLASP1

446 and TPX2, and biallelic deletion of CAMSAP3 and AKAP450 were confirmed by

447 immunoblotting with specific antibodies as follows: ch-TOG (QED Bioscience, 1:1,000),

448 CLASP1 (Abcam, 1:1,000), TPX2 (anti-rabbit, 1:200, a gift of Dr. Isabelle Vernos (Gruss

449 et al., 2002)), CAMSAP3 (anti-rabbit, 1:200, gift of Dr. Masatoshi Takeichi (Tanaka et

450 al., 2012)) and AKAP450 (anti-rabbit, 1:1,000, gift of Dr. Yoshitaka Ono (Takahashi et

451 al., 1999)). All tagged lines grew in a manner that was indistinguishable from the parental

452 line, indicating that the tag did not substantially affect protein function. To activate auxin-

453 inducible degradation, cells were treated with $2 \mu \mathrm{g} / \mathrm{mL}$ Dox for $20-24 \mathrm{~h}$ and $500 \mu \mathrm{M} \mathrm{IAA}$

454 for the duration indicated in each figure. RNAi was performed using Lipofectamine

455 RNAiMAX (Invitrogen), following manufacturer's instruction.

456

457

458 Immunoblotting was performed using a standard protocol with SDS sample buffer, except

459 for ch-TOG detection, which might be prone to degradation during this procedure. For

460 ch-TOG, cells were treated with $4 \mathrm{M}$ urea-containing sample buffer for $10 \mathrm{~min}$ at room

461 temperature (Ito and Goshima, 2015). Sucrose gradient centrifugation was performed

462 according to previously reported methods (Choi et al., 2010; Teixido-Travesa et al., 2010).

463 Confluent cells on three 10-cm culture dishes were lysed with $800 \mu \mathrm{L}$ lysis buffer (50

$464 \mathrm{mM}$ HEPES-KOH pH 7.6, $150 \mathrm{mM} \mathrm{NaCl}, 1 \mathrm{mM}$ EGTA, $1 \mathrm{mM} \mathrm{MgCl2,} 1 \mathrm{mM}$ DTT,

$4650.5 \%$ NP-40, $100 \mu \mathrm{M}$ GTP, and protease inhibitors), followed by $27 \mathrm{G}$ needle passages. 
466 After two rounds of centrifugation $(13,000 \mathrm{rpm}, 15 \mathrm{~min}$ in a tabletop centrifuge and $46750,000 \mathrm{rpm}, 15 \mathrm{~min}$ in TLA100.3 rotor [Beckmann]), $500 \mu \mathrm{L}$ supernatant was loaded 468 onto a $10 \%-40 \%$ sucrose gradient in a SETON tube (\#7022), which was prepared using 469 Gradient Station (BIOCOMP), and centrifuged in an MLS-50 rotor (Beckmann) at 50,000 $470 \mathrm{rpm}$ for $3 \mathrm{~h} 45 \mathrm{~min}$ at $4{ }^{\circ} \mathrm{C}$. Fractionation was performed with Gradient Station attached 471 to MicroCollector (AC-5700P, ATTO). Aldolase (7.4S) and thyroglobulin (19S) were 472 used as size markers.

Imaging was mostly performed using spinning-disc confocal microscopy with a $60 \times 1.40$ NA lens (Nikon). A CSU-X1 confocal unit (Yokogawa Electric Corporation) and an EMCCD camera ImagEM (Hamamatsu Photonics) were attached to a Ti-E inverted microscope (Nikon) with a perfect focus system. Several DIC images were acquired with another spinning-disc confocal microscope, in which CSU-W1 and ORCA-Flash4.0 digital CMOS camera (Hamamatsu Photonics) were attached to Ti-E (courtesy of Dr. Tomomi Kiyomitsu). Oblique illumination fluorescence microscopy was performed following the method used for plant cell imaging (Nakaoka et al., 2015). Briefly, the cortical region of interphase cells on the glass-bottom dish was imaged every $2 \mathrm{~s}$ with a Nikon Ti-E microscope equipped with an EMCCD camera Evolve (Roper) and the total internal reflection fluorescence unit and a $100 \times 1.49$ NA lens (Nikon). A fragment of broken glass was placed on the sample to flatten the cells. Imaging for regrowth assay was performed mostly at $25-26^{\circ} \mathrm{C}$ and sometimes at $37^{\circ} \mathrm{C}$ as indicated in the figure. Time-lapse imaging of regular mitosis and the degron efficiency analysis were performed at $37^{\circ} \mathrm{C}$. The microscopes were controlled using NIS-Elements software (Nikon). Centrin-2 immunostaining was performed with a specific antibody (SantaCruz, rabbit, 1:500) after methanol fixation. All image analyses of live spinning-discs were based on maximum projection images, whereas a single focal plane was shown for the immunofluorescence image and measurement of SiR-tubulin signals. To optimise the image brightness, the same linear adjustments were applied using Fiji. MT growth in prometaphase was determined at $30 \mathrm{~min}$; the appearance of filamentous signals emanating from MTOCs were the indicator of MT regrowth.

\section{MT regrowth assay}

The flowcharts are shown in the figures. In one mitosis experiment, typically 3-4 analysable cells were obtained; to obtain $\mathrm{N} \geq 10$, at least three independent experiments were performed. Cells were cultured in 4-well glass-bottomed dishes (CELLview ${ }^{\mathrm{TM}}$, \#627870; Greiner Bio-One, Kremsmünster, Austria) and maintained in a stage-top incubator (Tokai Hit, Fujinomiya, Japan). $5 \% \mathrm{CO}_{2}$ was supplied. The heater was not turned on, and the experiment was performed at room temperature $\left(\sim 25^{\circ} \mathrm{C}\right)$. MTs were stained with $50 \mathrm{nM} \mathrm{SiR-tubulin} \mathrm{(Spirochrome)} \mathrm{for}>1 \mathrm{~h}$ prior to image acquisition (Lukinavicius et al., 2014; Okumura et al., 2018). Cells in a 4-well glass-bottom dish were treated with $40 \mathrm{ng} / \mathrm{mL}$ nocodazole on ice for $4 \mathrm{~h}$ (interphase) or at $37^{\circ} \mathrm{C}$ for $20-24 \mathrm{~h}$ (prometaphase), followed by drug washout by medium exchange twice (1 min each, 700$800 \mu \mathrm{L}$, room temperature). This incubation time on ice was set as residual MTs or dead 511 immediately set under a microscope, and images were acquired. In most experiments, the 
cells were kept at room temperature $\left(\sim 25^{\circ} \mathrm{C}\right)$ to prevent MT nucleation before sample setup and slow down the nucleation step. For regrowth assay at $37^{\circ} \mathrm{C}$, cells were washed by $37^{\circ} \mathrm{C}$ warmed medium and the temperature was contoroled by stage top incubator. Images were acquired every $30 \mathrm{~s}$ for $30 \mathrm{~min}$ with spinning-disc microscopy equipped with a piezo stage $(1 \mu \mathrm{m} \times 3$ or $5 \mathrm{z}$-sections). The maximum projection images are displayed in the figures. Cells were treated with mitotic kinase inhibitors for $2 \mathrm{~h}$ prior to imaging, and imaging was performed in the presence of drug treatments (BI2336, $10 \mu \mathrm{M}$; ZM447439, $10 \mu \mathrm{M}$; and Alisertib, $0.5 \mu \mathrm{M}$ ). BI2536 was effective at this concentration in the HCT116-TubG1 degron line, as 16 out of 17 cells showed monopolar spindles at only $30 \mathrm{nM}$. ZM447439 was shown to be effective in HCT116 cells at concentrations of $2 \mu \mathrm{M}$ or higher (Dreier et al., 2009; Li et al., 2010). Moreover, we reproduced the phenotype using RNAi. The reported IC50 value of alisertib in HCT116 was $0.032 \mu \mathrm{M}$ (Manfredi et al., 2011) and $0.04 \mu \mathrm{M}$ (Davis et al., 2015), which is much lower than our applied concentration $(0.5 \mu \mathrm{M})$. Other studies have shown that $\mathrm{p} 53$ is fully activated at $0.4 \mu \mathrm{M}$ or above (Marxer et al., 2014) or that apoptosis is observed similarly at $0.1 \mu \mathrm{M}$ and $1 \mu \mathrm{M}$ (Pitts et al., 2016).

\section{Acknowledgments}

We would like to thank Tomomi Kiyomitsu for cell lines, reagents, and valuable comments on the manuscript, Marie Nishikawa for the selection of a cell line, Tomoko Nishiyama for help of sucrose gradient centrifugation, and Aoi Takeda for checking several cell lines. This work was funded by JSPS KAKENHI (17H01431), and JSPS and DFG under the Joint Research Projects-LEAD with UKRI to G.G. The authors declare no conflicts of interest.

\section{References}

Al-Bassam, J., H. Kim, G. Brouhard, A. van Oijen, S.C. Harrison, and F. Chang. 2010. CLASP promotes microtubule rescue by recruiting tubulin dimers to the microtubule. Dev Cell. 19:245-258.

Alfaro-Aco, R., A. Thawani, and S. Petry. 2020. Biochemical reconstitution of branching microtubule nucleation. Elife. 9.

Ayukawa, R., S. Iwata, H. Imai, S. Kamimura, M. Hayashi, K.X. Ngo, I. Minoura, S. Uchimura, T. Makino, M. Shirouzu, H. Shigematsu, K. Sekimoto, B. Gigant, and E. Muto. 2021. GTP-dependent formation of straight tubulin oligomers leads to microtubule nucleation. J Cell Biol. 220.

Brattain, M.G., W.D. Fine, F.M. Khaled, J. Thompson, and D.E. Brattain. 1981. Heterogeneity of malignant cells from a human colonic carcinoma. Cancer Res. 41:1751-1756.

Brouhard, G.J., J.H. Stear, T.L. Noetzel, J. Al-Bassam, K. Kinoshita, S.C. Harrison, J. Howard, and A.A. Hyman. 2008. XMAP215 is a processive microtubule polymerase. Cell. 132:79-88.

Brunet, S., T. Sardon, T. Zimmerman, T. Wittmann, R. Pepperkok, E. Karsenti, and I. Vernos. 2004. Characterization of the TPX2 domains involved in microtubule nucleation and spindle assembly in Xenopus egg extracts. Mol Biol Cell. 15:5318-5328.

Carmena, M., M. Wheelock, H. Funabiki, and W.C. Earnshaw. 2012. The chromosomal passenger complex (CPC): from easy rider to the godfather of mitosis. Nat Rev Mol Cell Biol. 13:789-803. 
Cavazza, T., P. Malgaretti, and I. Vernos. 2016. The sequential activation of the mitotic microtubule assembly pathways favors bipolar spindle formation. Mol Biol Cell. 27:2935-2945.

Chinen, T., P. Liu, S. Shioda, J. Pagel, B. Cerikan, T.C. Lin, O. Gruss, Y. Hayashi, H. Takeno, T. Shima, Y. Okada, I. Hayakawa, Y. Hayashi, H. Kigoshi, T. Usui, and E. Schiebel. 2015. The gamma-tubulin-specific inhibitor gatastatin reveals temporal requirements of microtubule nucleation during the cell cycle. Nat Commun. 6:8722.

Choi, Y.K., P. Liu, S.K. Sze, C. Dai, and R.Z. Qi. 2010. CDK5RAP2 stimulates microtubule nucleation by the gamma-tubulin ring complex. J Cell Biol. 191:1089-1095.

Consolati, T., J. Locke, J. Roostalu, Z.A. Chen, J. Gannon, J. Asthana, W.M. Lim, F. Martino, M.A. Cvetkovic, J. Rappsilber, A. Costa, and T. Surrey. 2020. Microtubule Nucleation Properties of Single Human gammaTuRCs Explained by Their Cryo-EM Structure. Dev Cell. 53:603-617 e608.

David, A.F., P. Roudot, W.R. Legant, E. Betzig, G. Danuser, and D.W. Gerlich. 2019. Augmin accumulation on long-lived microtubules drives amplification and kinetochore-directed growth. J Cell Biol. 218:2150-2168.

Davis, S.L., K.M. Robertson, T.M. Pitts, J.J. Tentler, E.L. Bradshaw-Pierce, P.J. Klauck, S.M. Bagby, S.L. Hyatt, H.M. Selby, A. Spreafico, J.A. Ecsedy, J.J. Arcaroli, W.A. Messersmith, A.C. Tan, and S.G. Eckhardt. 2015. Combined inhibition of MEK and Aurora A kinase in KRAS/PIK3CA double-mutant colorectal cancer models. Front Pharmacol. 6:120.

Dreier, M.R., A.Z. Grabovich, J.D. Katusin, and W.R. Taylor. 2009. Short and long-term tumor cell responses to Aurora kinase inhibitors. Exp Cell Res. 315:1085-1099.

Efimov, A., A. Kharitonov, N. Efimova, J. Loncarek, P.M. Miller, N. Andreyeva, P. Gleeson, N. Galjart, A.R. Maia, I.X. McLeod, J.R. Yates, 3rd, H. Maiato, A. Khodjakov, A. Akhmanova, and I. Kaverina. 2007. Asymmetric CLASP-dependent nucleation of noncentrosomal microtubules at the trans-Golgi network. Dev Cell. 12:917-930.

Flor-Parra, I., A.B. Iglesias-Romero, and F. Chang. 2018. The XMAP215 Ortholog Alp14 Promotes Microtubule Nucleation in Fission Yeast. Curr Biol. 28:1681-1691 e1684.

Gavilan, M.P., P. Gandolfo, F.R. Balestra, F. Arias, M. Bornens, and R.M. Rios. 2018. The dual role of the centrosome in organizing the microtubule network in interphase. EMBO Rep. 19.

Goodwin, S.S., and R.D. Vale. 2010. Patronin regulates the microtubule network by protecting microtubule minus ends. Cell. 143:263-274.

Gruss, O.J., M. Wittmann, H. Yokoyama, R. Pepperkok, T. Kufer, H. Sillje, E. Karsenti, I.W. Mattaj, and I. Vernos. 2002. Chromosome-induced microtubule assembly mediated by TPX2 is required for spindle formation in HeLa cells. Nat Cell Biol. 4:871-879.

Hannak, E., K. Oegema, M. Kirkham, P. Gonczy, B. Habermann, and A.A. Hyman. 2002. The kinetically dominant assembly pathway for centrosomal asters in Caenorhabditis elegans is gamma-tubulin dependent. J Cell Biol. 157:591-602.

Imasaki, T., S. Kikkawa, S. Niwa, Y. Saijo-Hamano, H. Shigematsu, K. Aoyama, K. Mitsuoka, M. Aoki, A. Sakamoto, Y. Tomabechi, N. Sakai, M. Shirouzu, S. Taguchi, Y. Yamagishi, T. Setsu, Y. Sakihama, T. Shimizu, E. Nitta, M. Takeichi, and R. Nitta. 2021. CAMSAP2 organizes a $\gamma$-tubulin-independent microtubule nucleation centre. bioRxiv.

Ito, A., and G. Goshima. 2015. Microcephaly protein Asp focuses the minus ends of spindle microtubules at the pole and within the spindle. J Cell Biol. 211:999-1009.

Jiang, K., S. Hua, R. Mohan, I. Grigoriev, K.W. Yau, Q. Liu, E.A. Katrukha, A.F. Altelaar, A.J. Heck, C.C. Hoogenraad, and A. Akhmanova. 2014. Microtubule minus-end stabilization by polymerization-driven CAMSAP deposition. Dev Cell. 28:295-309. 
Kamasaki, T., E. O'Toole, S. Kita, M. Osumi, J. Usukura, J.R. McIntosh, and G. Goshima. 2013. Augmin-dependent microtubule nucleation at microtubule walls in the spindle. $J$ Cell Biol. 202:25-33.

Katayama, H., K. Sasai, M. Kloc, B.R. Brinkley, and S. Sen. 2008. Aurora kinase-A regulates kinetochore/chromatin associated microtubule assembly in human cells. Cell Cycle. 7:2691-2704.

King, B.R., M. Moritz, H. Kim, D.A. Agard, C.L. Asbury, and T.N. Davis. 2020. XMAP215 and gamma-tubulin additively promote microtubule nucleation in purified solutions. Mol Biol Cell. 31:2187-2194.

King, M.R., and S. Petry. 2020. Phase separation of TPX2 enhances and spatially coordinates microtubule nucleation. Nat Commun. 11:270.

Leong, S.Y., M. Yamada, N. Yanagisawa, and G. Goshima. 2018. SPIRAL2 Stabilises Endoplasmic Microtubule Minus Ends in the Moss Physcomitrella patens. Cell Struct Funct. 43:53-60.

Li, M., A. Jung, U. Ganswindt, P. Marini, A. Friedl, P.T. Daniel, K. Lauber, V. Jendrossek, and C. Belka. 2010. Aurora kinase inhibitor ZM447439 induces apoptosis via mitochondrial pathways. Biochem Pharmacol. 79:122-129.

Liu, L., E. Tuzel, and J.L. Ross. 2011. Loop formation of microtubules during gliding at high density. J Phys Condens Matter. 23:374104.

Liu, P., M. Wurtz, E. Zupa, S. Pfeffer, and E. Schiebel. 2021. Microtubule nucleation: The waltz between gamma-tubulin ring complex and associated proteins. Curr Opin Cell Biol. 68:124-131.

Liu, P., E. Zupa, A. Neuner, A. Bohler, J. Loerke, D. Flemming, T. Ruppert, T. Rudack, C. Peter, C. Spahn, O.J. Gruss, S. Pfeffer, and E. Schiebel. 2020. Insights into the assembly and activation of the microtubule nucleator gamma-TuRC. Nature. 578:467471.

Logarinho, E., S. Maffini, M. Barisic, A. Marques, A. Toso, P. Meraldi, and H. Maiato. 2012. CLASPs prevent irreversible multipolarity by ensuring spindle-pole resistance to traction forces during chromosome alignment. Nat Cell Biol. 14:295-303.

Luders, J., U.K. Patel, and T. Stearns. 2006. GCP-WD is a gamma-tubulin targeting factor required for centrosomal and chromatin-mediated microtubule nucleation. Nat Cell Biol. 8:137-147.

Lukinavicius, G., L. Reymond, E. D'Este, A. Masharina, F. Gottfert, H. Ta, A. Guther, M. Fournier, S. Rizzo, H. Waldmann, C. Blaukopf, C. Sommer, D.W. Gerlich, H.D. Arndt, S.W. Hell, and K. Johnsson. 2014. Fluorogenic probes for live-cell imaging of the cytoskeleton. Nat Methods. 11:731-733.

Maffini, S., A.R. Maia, A.L. Manning, Z. Maliga, A.L. Pereira, M. Junqueira, A. Shevchenko, A. Hyman, J.R. Yates, 3rd, N. Galjart, D.A. Compton, and H. Maiato. 2009. Motorindependent targeting of CLASPs to kinetochores by CENP-E promotes microtubule turnover and poleward flux. Curr Biol. 19:1566-1572.

Magnaghi-Jaulin, L., G. Eot-Houllier, E. Gallaud, and R. Giet. 2019. Aurora A Protein Kinase: To the Centrosome and Beyond. Biomolecules. 9.

Manfredi, M.G., J.A. Ecsedy, A. Chakravarty, L. Silverman, M. Zhang, K.M. Hoar, S.G. Stroud, W. Chen, V. Shinde, J.J. Huck, D.R. Wysong, D.A. Janowick, M.L. Hyer, P.J. Leroy, R.E. Gershman, M.D. Silva, M.S. Germanos, J.B. Bolen, C.F. Claiborne, and T.B. Sells. 2011. Characterization of Alisertib (MLN8237), an investigational smallmolecule inhibitor of aurora A kinase using novel in vivo pharmacodynamic assays. Clin Cancer Res. 17:7614-7624.

Marxer, M., H.T. Ma, W.Y. Man, and R.Y. Poon. 2014. p53 deficiency enhances mitotic arrest and slippage induced by pharmacological inhibition of Aurora kinases. Oncogene. 33:3550-3560. 
660

661

662

663

664

665

666

667

668

669

670

671

672

673

674

675

676

677

678

679

680

681

682

683

684

685

686

687

688

689

690

691

692

693

694

695

696

697

698

699

700

701

702

703

704

705

706

707

708

709

McKinley, K.L., and I.M. Cheeseman. 2017. Large-Scale Analysis of CRISPR/Cas9 Cell-Cycle Knockouts Reveals the Diversity of p53-Dependent Responses to Cell-Cycle Defects. Dev Cell. 40:405-420 e402.

Moriwaki, T., and G. Goshima. 2016. Five factors can reconstitute all three phases of microtubule polymerization dynamics. $J$ Cell Biol. 215:357-368.

Motegi, F., N.V. Velarde, F. Piano, and A. Sugimoto. 2006. Two phases of astral microtubule activity during cytokinesis in C. elegans embryos. Dev Cell. 10:509-520.

Nakaoka, Y., A. Kimura, T. Tani, and G. Goshima. 2015. Cytoplasmic nucleation and atypical branching nucleation generate endoplasmic microtubules in Physcomitrella patens. Plant Cell. 27:228-242.

Natsume, T., T. Kiyomitsu, Y. Saga, and M.T. Kanemaki. 2016. Rapid Protein Depletion in Human Cells by Auxin-Inducible Degron Tagging with Short Homology Donors. Cell Rep. 15:210-218.

O'Toole, E.T., K.L. McDonald, J. Mantler, J.R. McIntosh, A.A. Hyman, and T. Muller-Reichert. 2003. Morphologically distinct microtubule ends in the mitotic centrosome of Caenorhabditis elegans. J Cell Biol. 163:451-456.

Oakley, C.E., and B.R. Oakley. 1989. Identification of gamma-tubulin, a new member of the tubulin superfamily encoded by mipA gene of Aspergillus nidulans. Nature. 338:662664.

Okumura, M., T. Natsume, M.T. Kanemaki, and T. Kiyomitsu. 2018. Dynein-Dynactin-NuMA clusters generate cortical spindle-pulling forces as a multi-arm ensemble. Elife. 7.

Pitts, T.M., E.L. Bradshaw-Pierce, S.M. Bagby, S.L. Hyatt, H.M. Selby, A. Spreafico, J.J. Tentler, K. McPhillips, P.J. Klauck, A. Capasso, J.R. Diamond, S.L. Davis, A.C. Tan, J.J. Arcaroli, A. Purkey, W.A. Messersmith, J.A. Ecsedy, and S.G. Eckhardt. 2016. Antitumor activity of the aurora a selective kinase inhibitor, alisertib, against preclinical models of colorectal cancer. Oncotarget. 7:50290-50301.

Rivero, S., J. Cardenas, M. Bornens, and R.M. Rios. 2009. Microtubule nucleation at the cisside of the Golgi apparatus requires AKAP450 and GM130. EMBO J. 28:1016-1028.

Rogers, G.C., N.M. Rusan, M. Peifer, and S.L. Rogers. 2008. A multicomponent assembly pathway contributes to the formation of acentrosomal microtubule arrays in interphase Drosophila cells. Mol Biol Cell. 19:3163-3178.

Roostalu, J., N.I. Cade, and T. Surrey. 2015. Complementary activities of TPX2 and chTOG constitute an efficient importin-regulated microtubule nucleation module. Nat Cell Biol. $17: 1422-1434$.

Roostalu, J., and T. Surrey. 2017. Microtubule nucleation: beyond the template. Nat Rev Mol Cell Biol. 18:702-710.

Sallee, M.D., J.C. Zonka, T.D. Skokan, B.C. Raftrey, and J.L. Feldman. 2018. Tissue-specific degradation of essential centrosome components reveals distinct microtubule populations at microtubule organizing centers. PLoS Biol. 16:e2005189.

Slep, K.C., and R.D. Vale. 2007. Structural basis of microtubule plus end tracking by XMAP215, CLIP-170, and EB1. Mol Cell. 27:976-991.

Takahashi, M., H. Shibata, M. Shimakawa, M. Miyamoto, H. Mukai, and Y. Ono. 1999. Characterization of a novel giant scaffolding protein, CG-NAP, that anchors multiple signaling enzymes to centrosome and the golgi apparatus. J Biol Chem. 274:1726717274.

Tanaka, N., W. Meng, S. Nagae, and M. Takeichi. 2012. Nezha/CAMSAP3 and CAMSAP2 cooperate in epithelial-specific organization of noncentrosomal microtubules. Proc Natl Acad Sci U S A. 109:20029-20034.

Tariq, A., L. Green, J.C.G. Jeynes, C. Soeller, and J.G. Wakefield. 2020. In vitro reconstitution of branching microtubule nucleation. Elife. 9. 
Teixido-Travesa, N., J. Villen, C. Lacasa, M.T. Bertran, M. Archinti, S.P. Gygi, C. Caelles, J. Roig, and J. Luders. 2010. The gammaTuRC revisited: a comparative analysis of interphase and mitotic human gammaTuRC redefines the set of core components and identifies the novel subunit GCP8. Mol Biol Cell. 21:3963-3972.

Thawani, A., R.S. Kadzik, and S. Petry. 2018. XMAP215 is a microtubule nucleation factor that functions synergistically with the gamma-tubulin ring complex. Nat Cell Biol. 20:575585.

Tovey, C.A., and P.T. Conduit. 2018. Microtubule nucleation by gamma-tubulin complexes and beyond. Essays Biochem. 62:765-780.

Tsuchiya, K., H. Hayashi, M. Nishina, M. Okumura, Y. Sato, M.T. Kanemaki, G. Goshima, and T. Kiyomitsu. 2021. Ran-GTP Is Non-essential to Activate NuMA for Mitotic SpindlePole Focusing but Dynamically Polarizes HURP Near Chromosomes. Curr Biol. 31:115-127 e113.

Tulu, U.S., C. Fagerstrom, N.P. Ferenz, and P. Wadsworth. 2006. Molecular requirements for kinetochore-associated microtubule formation in mammalian cells. Curr Biol. 16:536541.

Tungadi, E.A., A. Ito, T. Kiyomitsu, and G. Goshima. 2017. Human microcephaly ASPM protein is a spindle pole-focusing factor that functions redundantly with CDK5RAP2. $J$ Cell Sci. 130:3676-3684.

Wang, S., D. Wu, S. Quintin, R.A. Green, D.K. Cheerambathur, S.D. Ochoa, A. Desai, and K. Oegema. 2015. NOCA-1 functions with gamma-tubulin and in parallel to Patronin to assemble non-centrosomal microtubule arrays in C. elegans. Elife. 4:e08649.

Wieczorek, M., S. Bechstedt, S. Chaaban, and G.J. Brouhard. 2015. Microtubule-associated proteins control the kinetics of microtubule nucleation. Nat Cell Biol. 17:907-916.

Wieczorek, M., S.C. Ti, L. Urnavicius, K.R. Molloy, A. Aher, B.T. Chait, and T.M. Kapoor. 2021. Biochemical reconstitutions reveal principles of human gamma-TuRC assembly and function. J Cell Biol. 220.

Wieczorek, M., L. Urnavicius, S.C. Ti, K.R. Molloy, B.T. Chait, and T.M. Kapoor. 2020. Asymmetric Molecular Architecture of the Human gamma-Tubulin Ring Complex. Cell. 180:165-175 e116.

Wong, Y.L., J.V. Anzola, R.L. Davis, M. Yoon, A. Motamedi, A. Kroll, C.P. Seo, J.E. Hsia, S.K. Kim, J.W. Mitchell, B.J. Mitchell, A. Desai, T.C. Gahman, A.K. Shiau, and K. Oegema. 2015. Cell biology. Reversible centriole depletion with an inhibitor of Pololike kinase 4. Science. 348:1155-1160.

Woodruff, J.B., B. Ferreira Gomes, P.O. Widlund, J. Mahamid, A. Honigmann, and A.A. Hyman. 2017. The Centrosome Is a Selective Condensate that Nucleates Microtubules by Concentrating Tubulin. Cell. 169:1066-1077 e1010.

Wu, J., C. de Heus, Q. Liu, B.P. Bouchet, I. Noordstra, K. Jiang, S. Hua, M. Martin, C. Yang, I. Grigoriev, E.A. Katrukha, A.F.M. Altelaar, C.C. Hoogenraad, R.Z. Qi, J. Klumperman, and A. Akhmanova. 2016. Molecular Pathway of Microtubule Organization at the Golgi Apparatus. Dev Cell. 39:44-60.

Yu, N., L. Signorile, S. Basu, S. Ottema, J.H. Lebbink, K. Leslie, I. Smal, D. Dekkers, J. Demmers, and N. Galjart. 2016. Isolation of functional tubulin dimers and of tubulinassociated proteins from mammalian cells. Curr Biol. 26:1728-1736.

Zheng, Y., R.A. Buchwalter, C. Zheng, E.M. Wight, J.V. Chen, and T.L. Megraw. 2020. A perinuclear microtubule-organizing centre controls nuclear positioning and basement membrane secretion. Nat Cell Biol. 22:297-309.

Zheng, Y., M.L. Wong, B. Alberts, and T. Mitchison. 1995. Nucleation of microtubule assembly by a gamma-tubulin-containing ring complex. Nature. 378:578-583. 


\section{Movie 1. Mitotic localisation of tagged proteins}

mClover-tagged TubG1 and mCherry-tagged ch-TOG, CLASP1, and TPX2 were imaged with MTs (visualised with SiR-tubulin) using spinning-disc confocal microscopy. Time indicates hours and minutes. Bar, $10 \mu \mathrm{m}$.

\section{Movie 2. Spindle phenotype after $\gamma$-tubulin depletion}

Mitotic progression after $\gamma$-tubulin depletion. MTs (green) were visualised using SiRtubulin and imaging was performed using spinning-disc confocal microscopy. Magenta; TubG1-mClover. Time is shown in hours and minutes.

\section{Movie 3. MT regrowth after depolymerisation in interphase}

Indicated proteins were depleted by AID in cells marked in white circles. MTs were visualised by SiR-tubulin and imaged using spinning-disc confocal microscopy. Time indicates minutes and seconds.

\section{Movie 4. MT regrowth after depolymerisation in interphase-oblique illumination}

MT regrowth in a $\gamma$-tubulin-depleted cell was observed using oblique illumination fluorescence microscopy. The region near the cell cortex was visualised using microscopy. Ring-shaped MTs are indicated by arrows. Time indicates minutes and seconds.

\section{Movie 5. MT regrowth after depolymerisation in mitosis}

The indicated proteins were depleted by AID in the white-circled cells. MTs were visualised by SiR-tubulin and imaged using spinning-disc confocal microscopy. Multiple ncMTOCs were detected in the $\gamma$-tubulin single-depleted cells. Time indicates minutes and seconds.

Table S1. Plasmids for homologous recombination

\begin{tabular}{|c|c|c|c|c|}
\hline \multirow[t]{2}{*}{ Name } & \multirow[t]{2}{*}{ Purpose } & \multicolumn{2}{|c|}{ Homology arm } & \multirow[t]{2}{*}{ Selection } \\
\hline & & $\mathbf{N}$ term & C term & \\
\hline pKT1 & TubG1-mClover-mAID integration & $248 \mathrm{bp}$ & $202 \mathrm{bp}$ & G418 \\
\hline pKT11 & TubG2 knock out & $642 \mathrm{bp}$ & $526 \mathrm{bp}$ & blasticidin \\
\hline pKT35 & ch-TOG-mAID-mCherry integration & $600 \mathrm{bp}$ & 669 bp & hygromycin \\
\hline pKT52 & ch-TOG-mCherry integration & $600 \mathrm{bp}$ & $669 \mathrm{bp}$ & hygromycin \\
\hline pKT90 & CLASP1-mAID-mCherry integration & $574 \mathrm{bp}$ & $632 \mathrm{bp}$ & hygromycin \\
\hline pKT43 & TPX2-mAID-mCherry integration & $201 \mathrm{bp}$ & $254 \mathrm{bp}$ & hygromycin \\
\hline pKT53 & TPX2-mCherry integration & $201 \mathrm{bp}$ & $254 \mathrm{bp}$ & hygromycin \\
\hline pKT55 & AKAP450 knock out & 598 bp & $601 \mathrm{bp}$ & hygromycin \\
\hline pKT58 & CAMSAP3 knock out & $834 \mathrm{bp}$ & $585 \mathrm{bp}$ & hygromycin \\
\hline
\end{tabular}


790 Table S2. sgRNA sequences for CRISPR/Cas9-mediated genome editing

\begin{tabular}{|l|l|l|l|}
\hline \multicolumn{1}{|c|}{ Gene } & \multicolumn{1}{|c|}{ sgRNA (5'-3') } & \multicolumn{1}{c|}{ PAM } & \multicolumn{1}{c|}{ plasmid } \\
\hline TubG1 & AGTCTGGCCGTGTGGCCGCA & TGG & pTK611 \\
\hline $\begin{array}{l}\text { TubG2 } \\
\text { (N-terminus) }\end{array}$ & TGCAGGGTGATGATCTCCCG & GGG & pKT13 \\
\hline $\begin{array}{l}\text { TubG2 } \\
\text { (C-terminus) }\end{array}$ & CTAGAAGGAGAAGGAGTAGT & GGG & pKT14 \\
\hline ch-TOG & CTGCAGGGTGCCGGGGGAGT & GGG & pKT36 \\
\hline CLASP1 & CCTGGGCTGATACGCACACC & TGG & pKT76 \\
\hline TPX2 & GAAATCCGAGGGGGCATCAT & AGG & pTK526 \\
\hline $\begin{array}{l}\text { AKAP450 } \\
\text { (N-terminus) }\end{array}$ & GCTGGAGGCCGGCAAAGCCA & AGG & pKT7 \\
\hline $\begin{array}{l}\text { AKAP450 } \\
\text { (C-terminus) }\end{array}$ & GAGCTGTGGGTCTCGCACTG & TGG & pKT8 \\
\hline $\begin{array}{l}\text { CAMSAP3 } \\
\text { (N-terminus) }\end{array}$ & TGGACCAGTACGATTTCTCG & CGG & pKT56 \\
\hline $\begin{array}{l}\text { CAMSAP3 } \\
\text { (C-terminus) }\end{array}$ & GGTGAAGGCATCGACGCTCA & TGG & pKT57 \\
\hline
\end{tabular}

Table S3. PCR primers to confirm gene editing

\begin{tabular}{|c|c|c|}
\hline Gene & Primer sequences (5'-3') & \\
\hline \multirow{2}{*}{$\begin{array}{l}\text { TubG1 } \\
\text { (C-terminus) }\end{array}$} & CCAAGCTCTTCGAGAGAAC & oTK848 \\
\hline & GTGTTTGCAGGCCAACAG & oTK849 \\
\hline \multirow{2}{*}{$\begin{array}{l}\text { TubG1 } \\
\text { (exon2,3) }\end{array}$} & GTCСТTТССТCAGACACGGG & oKT107 \\
\hline & ACGTCATAGAGCCTGTCCCT & oKT108 \\
\hline \multirow{2}{*}{$\begin{array}{l}\text { TubG2 } \\
\text { (5' upstream) }\end{array}$} & GCCAAGGCAGGAGGATTGAT & oKT33 \\
\hline & TTTTCTCCCTCAGCAGTCGC & oKT97 \\
\hline \multirow{2}{*}{$\begin{array}{l}\text { TubG2 } \\
\text { (exon1) }\end{array}$} & ACACGGTGAGATCCCCATCT & oKT38 \\
\hline & CATGGAAGGGAAAGGGGGAC & oKT34 \\
\hline \multirow{2}{*}{$\begin{array}{l}\text { TubG2 } \\
\text { (exon2-4) }\end{array}$} & CAGTTGGGTTCGAGTTCTGGA & oKT98 \\
\hline & CССССАСТCСАТАACTTCACC & oKT99 \\
\hline \multirow{2}{*}{$\begin{array}{l}\text { TubG2 } \\
(\text { exon5,6) }\end{array}$} & GTTGTGAGAGTGTGGCAGGA & oKT147 \\
\hline & TTCTGCGTCAGCCTCTTGAG & oKT101 \\
\hline TubG2 & TTCTCTCCACCСТCCСТCTG & oKT150 \\
\hline
\end{tabular}




\begin{tabular}{|c|c|c|}
\hline (exon7-11) & GAGCTCCTGAACAACCTCCC & oKT105 \\
\hline \multirow{2}{*}{$\begin{array}{l}\text { TubG2 } \\
\text { (3'UTR) }\end{array}$} & TTCCATTGGCATCCCTCACC & oKT151 \\
\hline & GGGAAGTCTGGACACCACAG & oKT152 \\
\hline \multirow{2}{*}{$\begin{array}{l}\text { ch-TOG } \\
\text { (C-terminus) }\end{array}$} & TCAGCCCTGGGATTACTGGA & oKT117 \\
\hline & CTTGTGTGCCTTTGGTCAGC & oKT118 \\
\hline \multirow{2}{*}{$\begin{array}{l}\text { CLASP1 } \\
\text { (C-terminus) }\end{array}$} & CTTGGCGAGGGAGTTTCACT & oKT304 \\
\hline & CCCACTTGCCAATTCCTCCT & oKT305 \\
\hline \multirow{2}{*}{$\begin{array}{l}\text { TPX2 } \\
\text { (N-terminus) }\end{array}$} & CCACTGCTCCTGGCCTAAAA & oKT196 \\
\hline & TGTGGCTGCCATCACTACAG & oKT172 \\
\hline \multirow{2}{*}{$\begin{array}{l}\text { AKAP450 } \\
\text { (N-terminus) }\end{array}$} & GAGGGAGGGACTTTTCAGGC & oKT27 \\
\hline & CACCCTGGAAAGCACAATGC & oKT286 \\
\hline \multirow{2}{*}{$\begin{array}{l}\text { AKAP450 } \\
\text { (Full length) }\end{array}$} & CAGGTAGGCTCAGGGAGGAT & $\mathrm{oKT} 285$ \\
\hline & CCCCCAAGGTGGAGTGTTAC & oKT287 \\
\hline \multirow{2}{*}{$\begin{array}{l}\text { CAMSAP3 } \\
\text { (N-terminus) }\end{array}$} & ACTCCTGCATTGACAGAGGC & oKT219 \\
\hline & AATCGTACTGGTCCAGCGAC & oKT258 \\
\hline \multirow{2}{*}{$\begin{array}{l}\text { CAMSAP3 } \\
\text { (C-terminus) }\end{array}$} & AGGTCCACGGCTGTACAAAG & oKT288 \\
\hline & GACTTTGCAGGGAGGTGACA & oKT222 \\
\hline
\end{tabular}

Table S4. Primers for RNAi

\begin{tabular}{|l|l|l|}
\hline \multicolumn{1}{|c|}{ siRNA } & \multicolumn{1}{c|}{ Sequences (5'-3') } & \multicolumn{1}{c|}{ Note } \\
\hline Luciferase & CGUACGCGGAAUACUUCGATT & Goshima et al., 2008 \\
\hline CDK5RAP2 & UGGAAGAUCUCCUAACUAATT & Fong et al, 2008 \\
\hline pericentrin & GCAGCUGAGCUGAAGGAGATT & $\begin{array}{l}\text { Dammermann and Merdes, } \\
2002\end{array}$ \\
\hline AKAP450 & AACUUUGAAGUUAACUAUCAA & Wang et al., 2010 \\
\hline NEDD1 & GCAGACAUGUGUCAAUUUATT & Lüders et al., 2006 \\
\hline HAUS6 & CAGUUAAGCAGGUACGAAATT & Goshima et al., 2008 \\
\hline HSET & UCAGAAGCAGCCCUGUCAATT & Cai et al., 2009 \\
\hline NuSAP & GGUGCAAGACUGUCCGUGUTT & Sironi et al., 2011 \\
\hline ch-TOG & GAGCCCAGAGUGGUCCAAA & $\begin{array}{l}\text { Cassimeris and Morabito, } \\
\text { 2004 }\end{array}$ \\
\hline CLASP1 & GGAUGAUUUACAAGACUGGTT & Kiyosue et al., 2005 \\
\hline CLASP2 & GACAUACAUGGGUCUUAGATT & Kiyosue et al., 2005 \\
\hline CAMSAP1 & CAUCGAGAAGCUUAACGAATT & Wei et al., 2017 \\
\hline CAMSAP2 & UUGCAUGUGCUCAACAGUTT & Yau et al., 2014 \\
\hline CAMSAP3 & CAGCAGCCACCAACUCCGAGGUGAAT & Meng et al., 2008 \\
\hline DHC & GCCAAAAGUUACAGACUUUTT & Splinter et al., 2008 \\
\hline TPX2 & GGGCAAAACUCCUUUGAGATT & Bird and Hyman 2008 \\
\hline Aurora B & GUCCCAGAUAGAGAAGGAGTT & Yüce et al., 2005 \\
\hline
\end{tabular}




\section{References for Table S4}

Bird, A.W., and A.A. Hyman. 2008. Building a spindle of the correct length in human cells requires the interaction between TPX2 and Aurora A. J Cell Biol. 182:289-300.

Cai, S., L.N. Weaver, S.C. Ems-McClung, and C.E. Walczak. 2009. Kinesin-14 family proteins HSET/XCTK2 control spindle length by cross-linking and sliding microtubules. Mol Biol Cell. 20:1348-1359.

Cassimeris, L., and J. Morabito. 2004. TOGp, the human homolog of XMAP215/Dis1, is required for centrosome integrity, spindle pole organization, and bipolar spindle assembly. Mol Biol Cell. 15:1580-1590.

Dammermann, A., and A. Merdes. 2002. Assembly of centrosomal proteins and microtubule organization depends on PCM-1. J Cell Biol. 159:255-266.

Fong, K.W., Y.K. Choi, J.B. Rattner, and R.Z. Qi. 2008. CDK5RAP2 is a pericentriolar protein that functions in centrosomal attachment of the gamma-tubulin ring complex. Mol Biol Cell. 19:115125.

Goshima, G., M. Mayer, N. Zhang, N. Stuurman, and R.D. Vale. 2008. Augmin: a protein complex required for centrosome-independent microtubule generation within the spindle. $J$ Cell Biol. 181:421-429.

Luders, J., U.K. Patel, and T. Stearns. 2006. GCP-WD is a gamma-tubulin targeting factor required for centrosomal and chromatin-mediated microtubule nucleation. Nat Cell Biol. 8:137-147.

Meng, W., Y. Mushika, T. Ichii, and M. Takeichi. 2008. Anchorage of microtubule minus ends to adherens junctions regulates epithelial cell-cell contacts. Cell. 135:948-959.

Mimori-Kiyosue, Y., I. Grigoriev, G. Lansbergen, H. Sasaki, C. Matsui, F. Severin, N. Galjart, F. Grosveld, I. Vorobjev, S. Tsukita, and A. Akhmanova. 2005. CLASP1 and CLASP2 bind to EB1 and regulate microtubule plus-end dynamics at the cell cortex. J Cell Biol. 168:141-153.

Sironi, L., J. Solon, C. Conrad, T.U. Mayer, D. Brunner, and J. Ellenberg. 2011. Automatic quantification of microtubule dynamics enables RNAi-screening of new mitotic spindle regulators. Cytoskeleton (Hoboken). 68:266-278.

Splinter, D., M.E. Tanenbaum, A. Lindqvist, D. Jaarsma, A. Flotho, K.L. Yu, I. Grigoriev, D. Engelsma, E.D. Haasdijk, N. Keijzer, J. Demmers, M. Fornerod, F. Melchior, C.C. Hoogenraad, R.H. Medema, and A. Akhmanova. 2010. Bicaudal D2, dynein, and kinesin-1 associate with nuclear pore complexes and regulate centrosome and nuclear positioning during mitotic entry. PLoS Biol. 8:e1000350.

Wang, Z., T. Wu, L. Shi, L. Zhang, W. Zheng, J.Y. Qu, R. Niu, and R.Z. Qi. 2010. Conserved motif of CDK5RAP2 mediates its localization to centrosomes and the Golgi complex. J Biol Chem. 285:22658-22665.

Wei, J., H. Xu, and W. Meng. 2017. Noncentrosomal microtubules regulate autophagosome transport through CAMSAP2-EB1 cross-talk. FEBS Lett. 591:2379-2393.

Yau, K.W., S.F. van Beuningen, I. Cunha-Ferreira, B.M. Cloin, E.Y. van Battum, L. Will, P. Schatzle, R.P. Tas, J. van Krugten, E.A. Katrukha, K. Jiang, P.S. Wulf, M. Mikhaylova, M. Harterink, R.J. Pasterkamp, A. Akhmanova, L.C. Kapitein, and C.C. Hoogenraad. 2014. Microtubule minus-end binding protein CAMSAP2 controls axon specification and dendrite development. Neuron. 82:1058-1073.

Yuce, O., A. Piekny, and M. Glotzer. 2005. An ECT2-centralspindlin complex regulates the localization and function of RhoA. J Cell Biol. 170:571-582. 
A

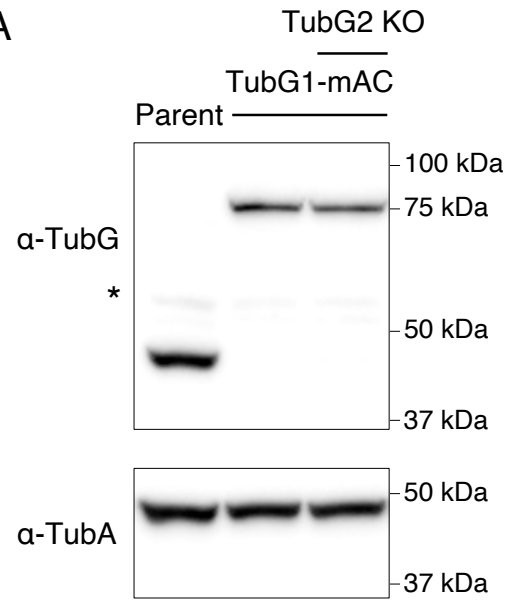

B

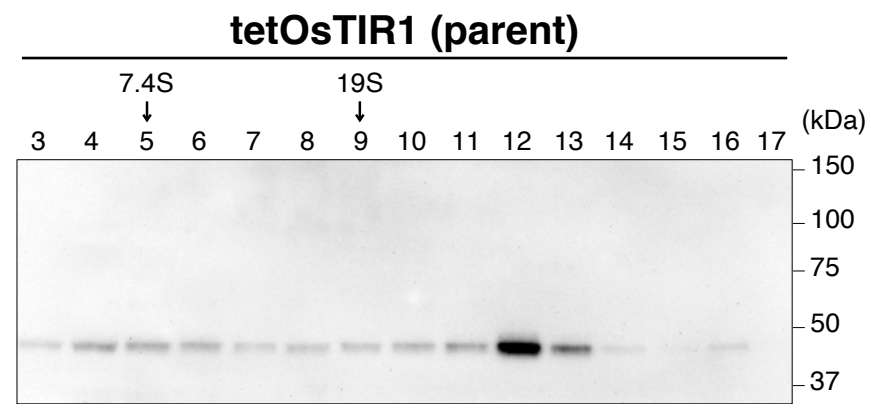

C

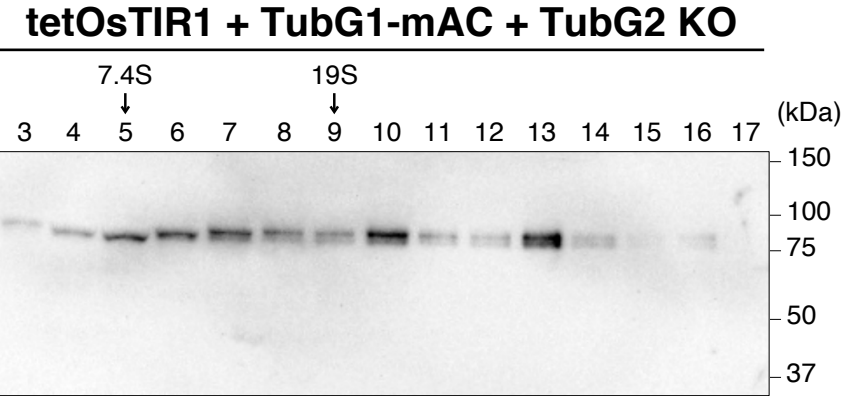

D Mitotic phenotype

Control

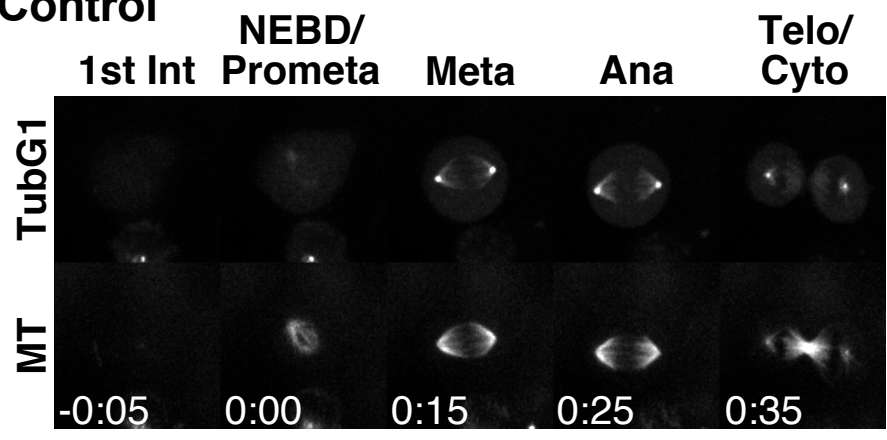

+Dox, IAA
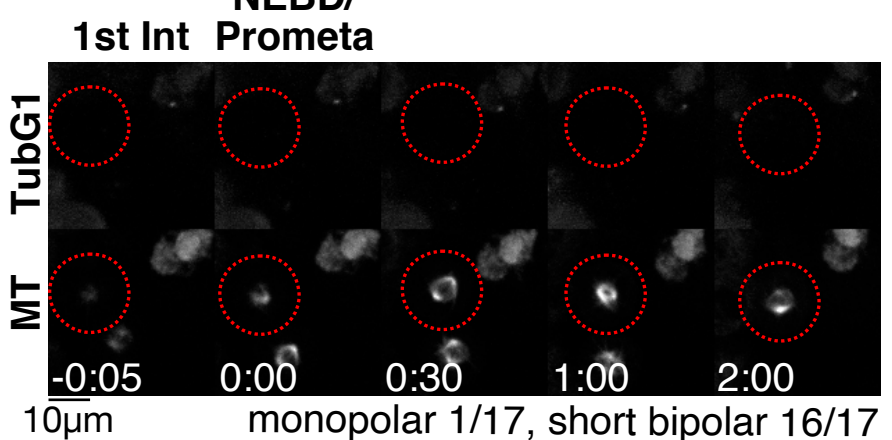

$\mathrm{E}$
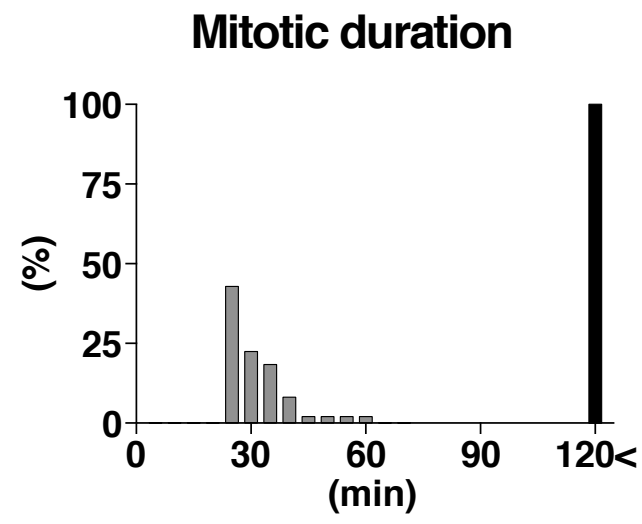

control $(n=49)$

- TubG1 degron $(n=17)$

Figure 1. Basic characterisation of TubG1 mAID-mClover cell line

(A) Immunoblotting of $\gamma$-tubulin and $\alpha$-tubulin for TubG1-mAID-mClover lines (TubG2 intact and KO lines) and the parental line. (B, C) Sucrose gradient centrifugation followed by immunoblotting of $\gamma$ tubulin for parent line (B) and TubG1-mAID-mClover line (C). (D) Spindle dynamics in TubG1depleted cells (TubG2 KO background) and control cells. Time 0 corresponds to NEBD. (E) Mitotic duration (NEBD to anaphase onset) of $\gamma$-tubulin-depleted cells. 
A TubG1-mAID-mClover \& TubG2 KO +Dox/IAA 24hr

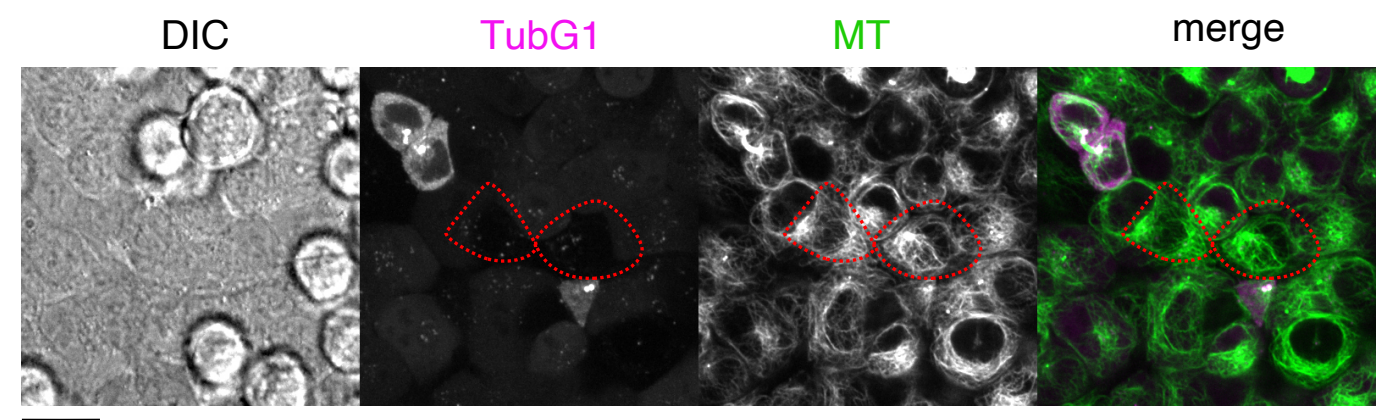

$\overline{20 \mu \mathrm{m}}$

B

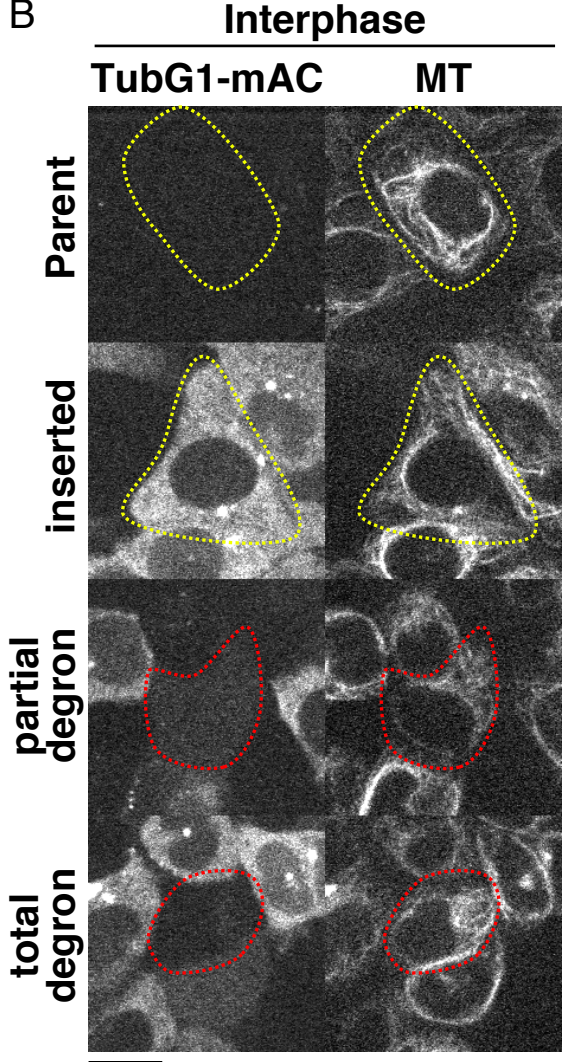

$\overline{10 \mu \mathrm{m}}$
C

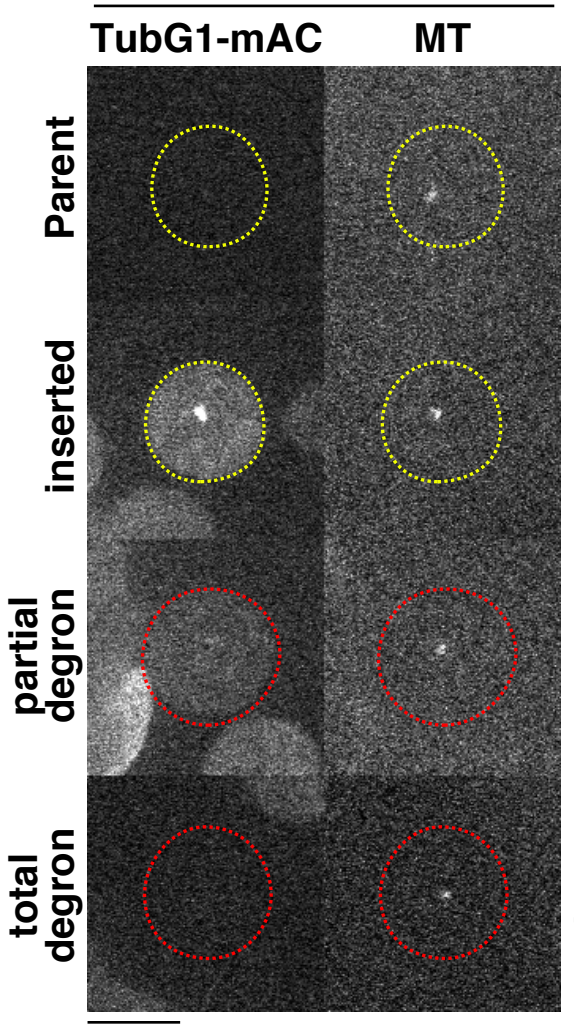

$\overline{10 \mu \mathrm{m}}$
D Interphase degron efficiency

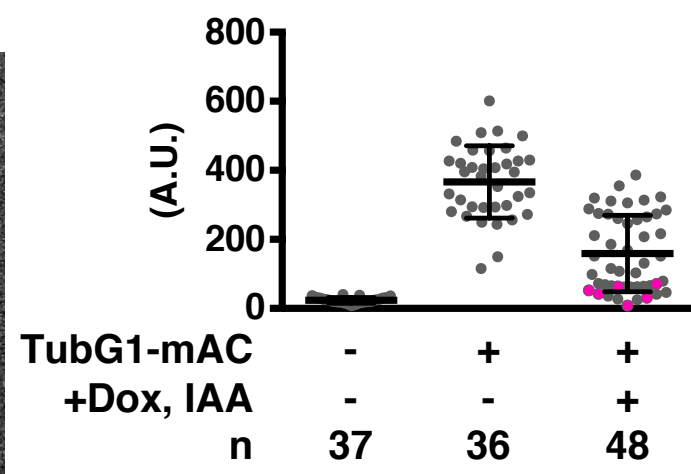

$\mathrm{E}$

Mitosis degron efficiency

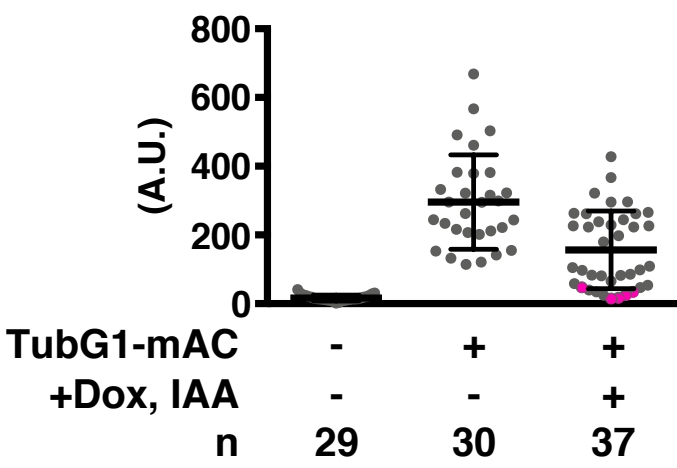

Figure 2. Quantitative assessment of $\boldsymbol{\gamma}$-tubulin depletion by AID

(A) MTs are present in cells with undetectable levels of $\gamma$-tubulin. Dox/IAA treatment induced degradation of $\gamma$-tubulin-mClover in majority of the cells (two representative cells are marked in red circles). (B, C) TubG1-mClover signals in interphase (B) and mitosis (C). Cells circled in red or yellow circles were treated or untreated with Dox/ IAA, respectively. Cells in mitosis were treated with nocodazole to depolymerise most MTs (remaining punctate signals correspond to centrioles). (D, E) Quantification of the mClover signal intensity in the indicated cell lines in interphase (D) and mitosis (E). Total cellular signal intensity was measured at a single focal plane that contained centrioles. Magenta-coloured dots indicate the cells for which an observer manually judged as "signals undetected". 
bioRxiv preprint doi: https://doi.org/10.1101/2021.08.13.456214; this version posted August 13, 2021. The copyright holder for this preprint (which was not certified by peer review) is the author/funder, who has granted bioRxiv a license to display the preprint in perpetuity. It is made available under aCC-BY-NC 4.0 International license.

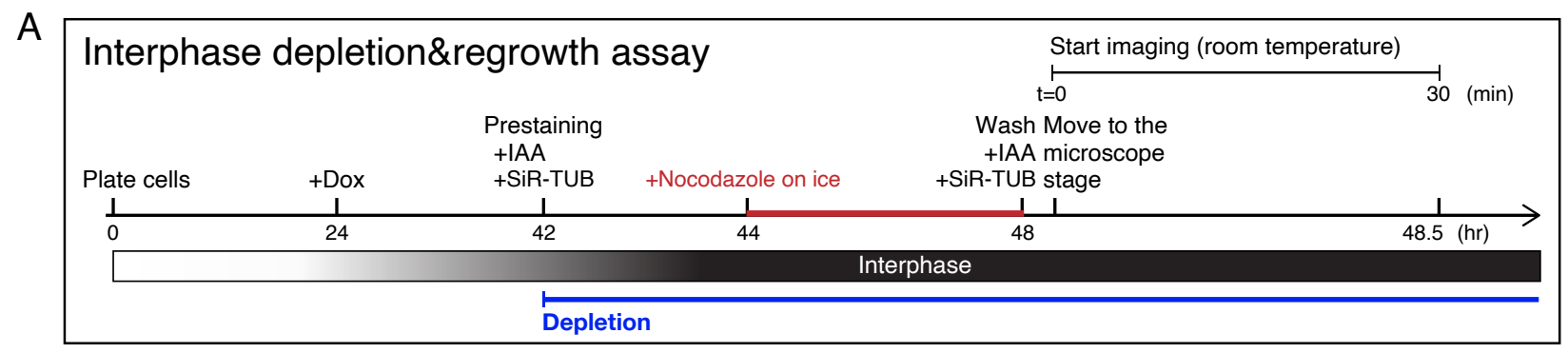

\section{B Interphase regrowth in TubG1 degron}

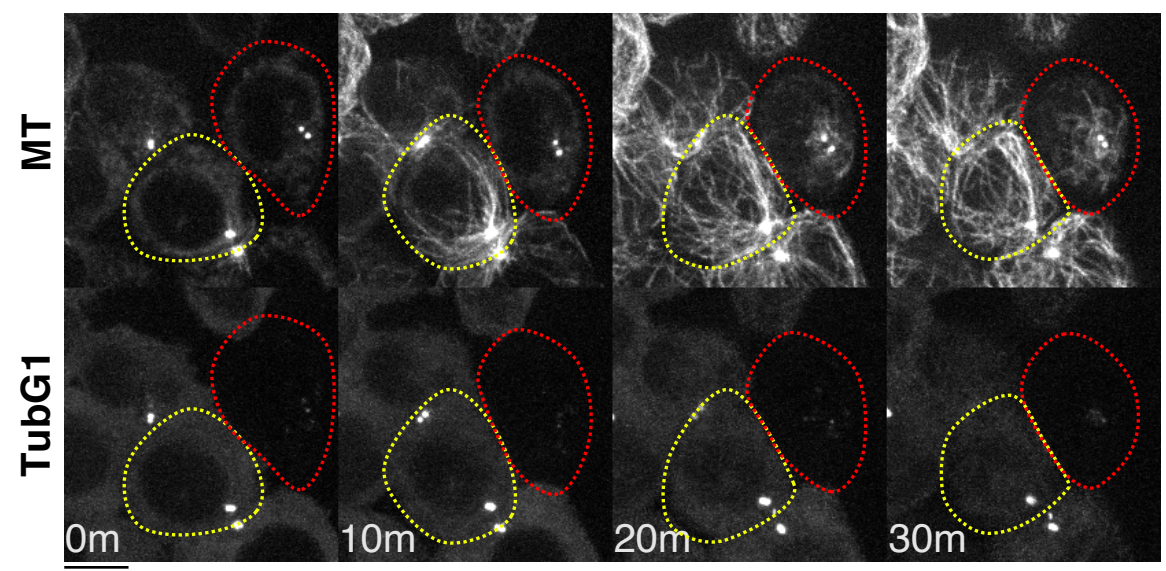

$10 \mu \mathrm{m}$

\section{Figure 3. MT nucleation without $\gamma$-tubulin}

(A) Flowchart of interphase MT depolymerisation-regrowth assay combined with auxin-induced degron. (B) $\gamma$-Tubulin-independent MT generation in interphase cells. MTs were depolymerised, except at the centrioles $(0 \mathrm{~min})$, followed by induction of regrowth $(10-30 \mathrm{~min})$. In the presence of $\gamma$ tubulin, MTs start to regrow within $10 \mathrm{~min}$ (yellow), whereas it took $>10 \mathrm{~min}$ in the absence (red). The faint signals after TubG1 depletion represent autofluorescence. 


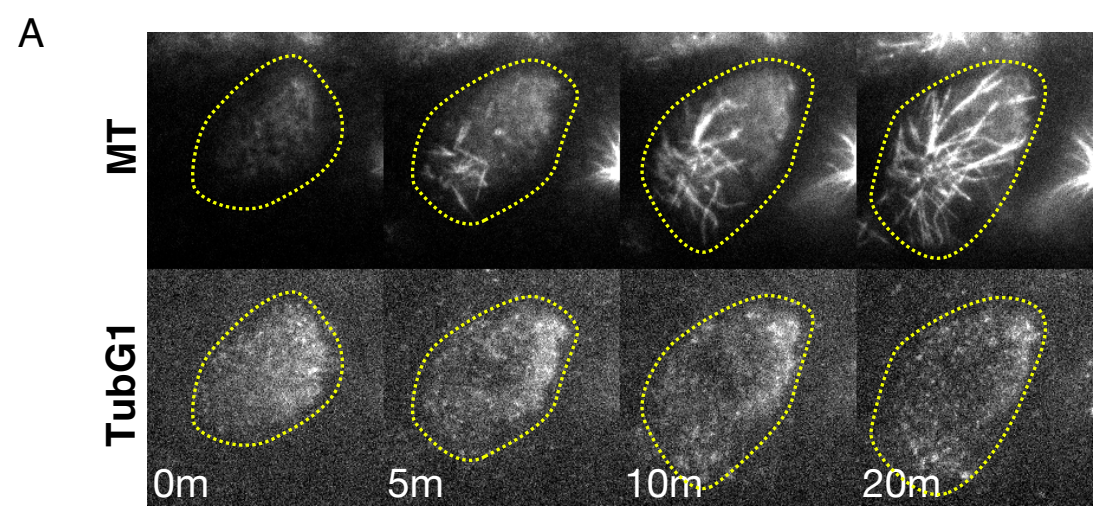

\section{MT appearance}
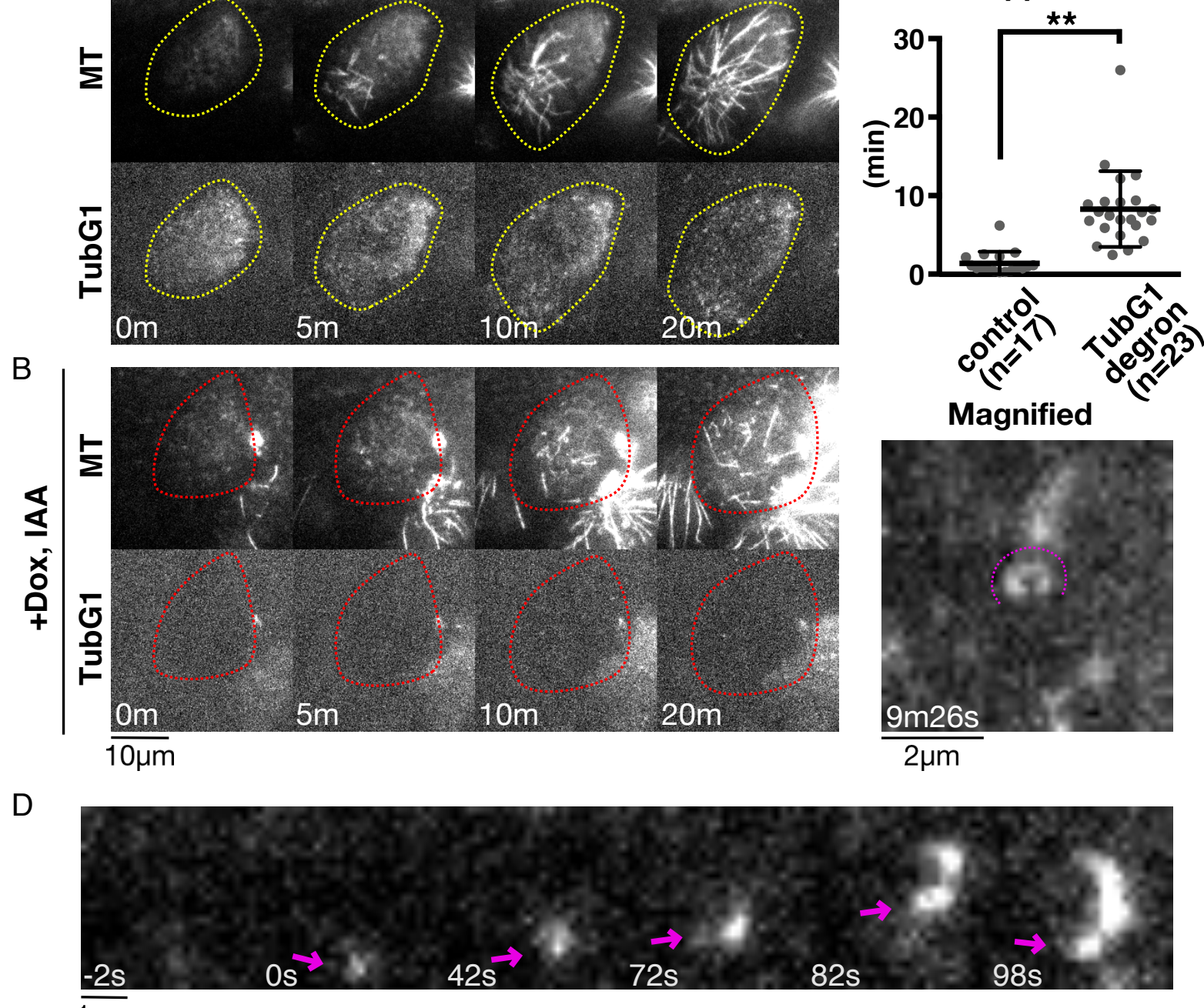

$\overline{1 \mu \mathrm{m}}$

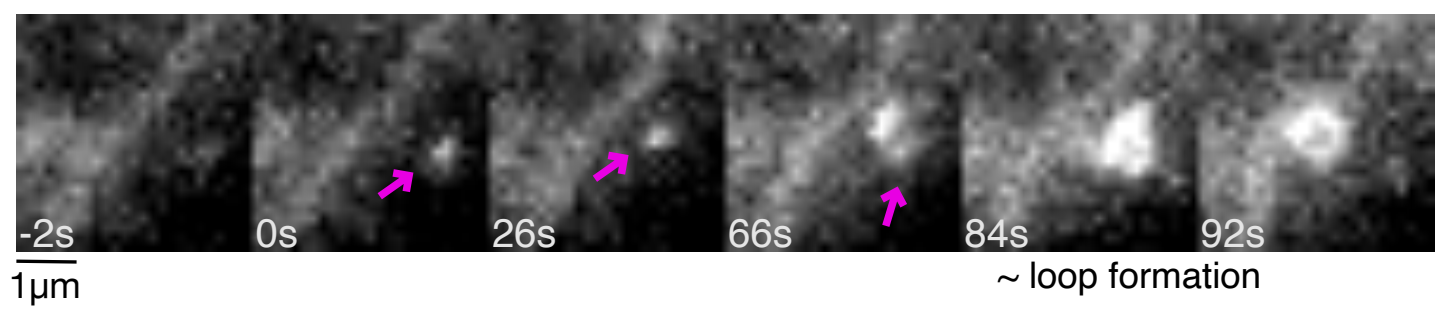

\section{Figure 4. Visualisation of $\gamma$-tubulin-independent MT nucleation}

(A, B) MT nucleation in the presence (A) or absence (B) of $\gamma$-tubulin. Images were acquired every $2 \mathrm{~s}$ with oblique illumination fluorescence microscopy, which allows the detection of individual $\gamma$-tubulin complex. (C) Time of first MT appearance after drug washout in the presence (1.4 $\pm 1.5 \mathrm{~min}$ [SD]) or absence $(8.3 \pm 4.8 \mathrm{~min})$ of $\gamma$-tubulin. MT was counted when the first SiR-tubulin signal stronger than the background was detected in three consecutive frames (i.e. $6 \mathrm{~s}$ ). $\mathrm{p}<0.0001$ (unpaired t-test with Welch's correction). (D) Two examples of nucleating MTs in the absence of $\gamma$-tubulin. The minus ends of nucleating MTs are marked with arrows. MT loop is formed in the second example (84-92 s). 


\section{A TubG1 degron \& RNAi screening}

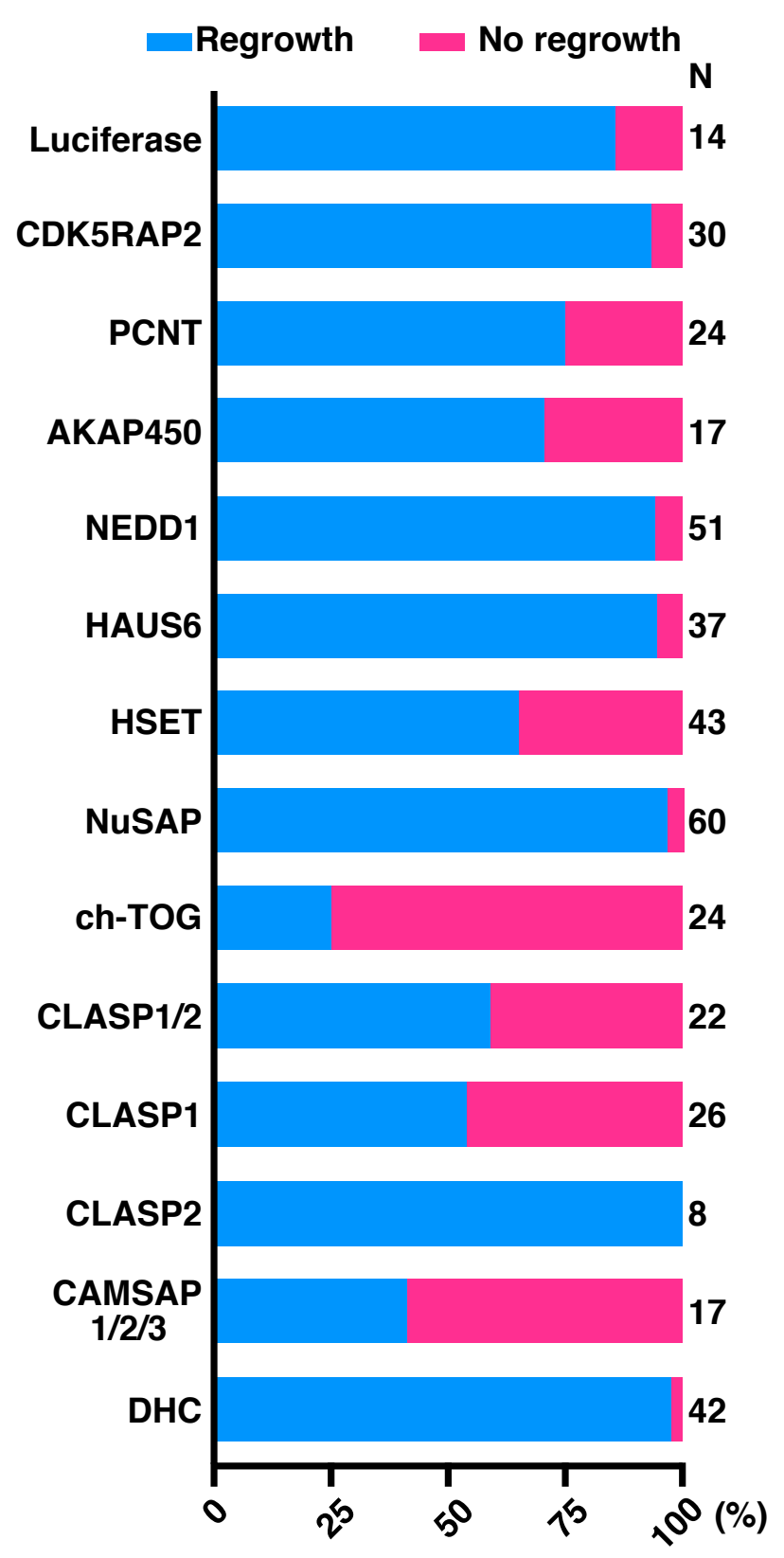

B TubG1 degron \& Luc RNAi

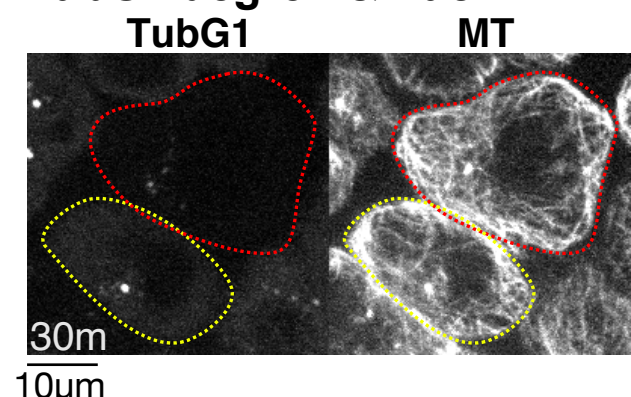

C TubG1 degron \& CLASP1/2 RNAi TubG1 MT

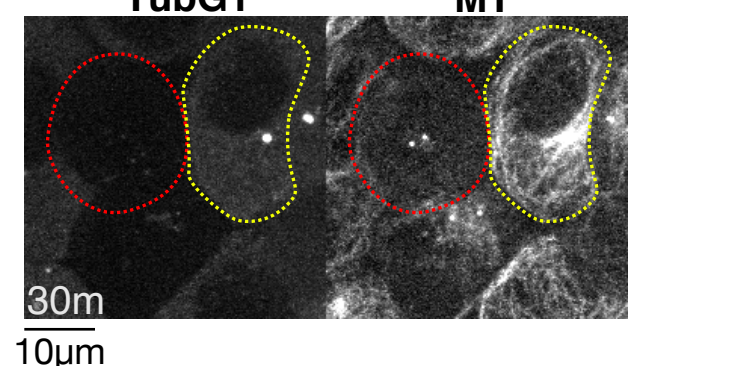

D TubG1 degron \& ch-TOG RNAi TubG1

MT

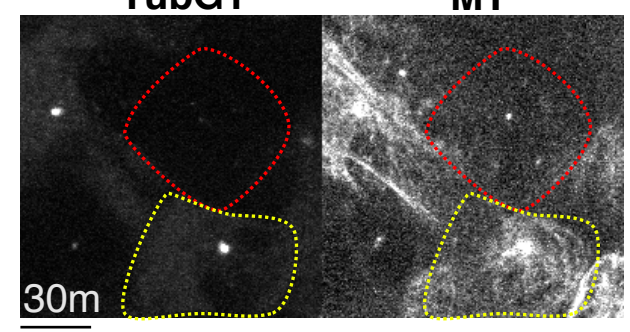

$\overline{10 \mu \mathrm{m}}$

E TubG1 degron \& CAMSAP1/2/3 RNAi

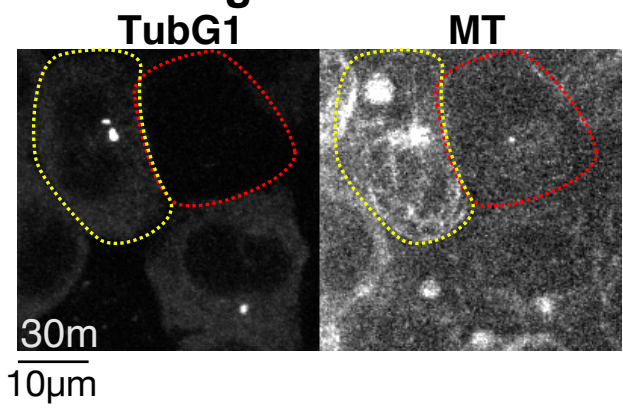

Figure 5. ch-TOG, CLASP1, and CAMSAP1/2 are critical for $\gamma$-tubulin-independent MT generation in interphase

(A) Frequency of MT regrowth after RNAi-mediated depletion of the indicated genes (30 min). RNAi cocktails targetted two or three genes simultaneously for CLASP or CAMSAP, respectively.

Luiciferase siRNA was used as a negative control. (B-E) $\gamma$-Tubulin degron was combined with RNAi of the indicated genes. Images were taken $30 \mathrm{~min}$ after nocodazole washout. Cells with $\gamma$-tubulin signals are indicated by yellow circles, whereas red-circled cells have no detectable $\gamma$-tubulin signals. 


\section{A TubG1\&ch-TOG degron}

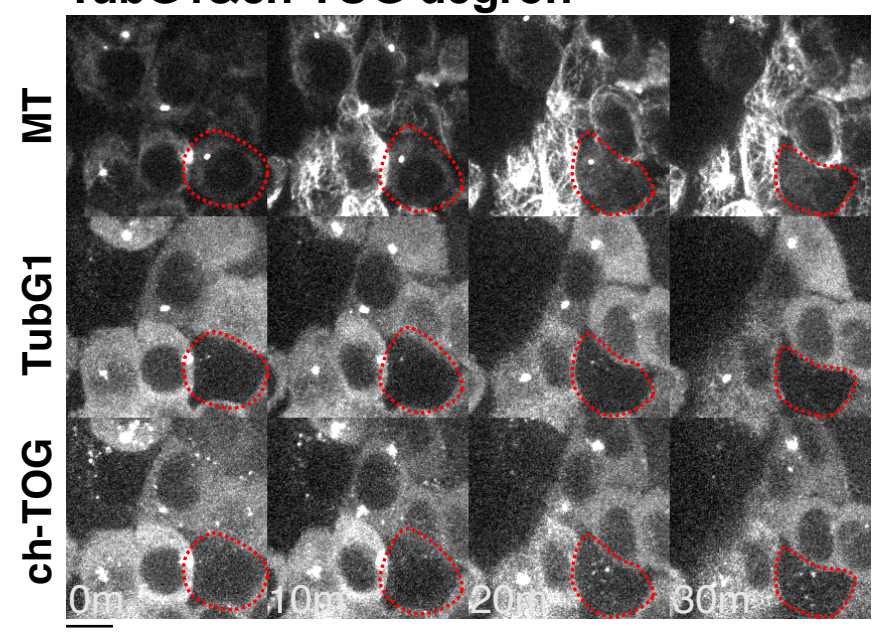

B TubG1\&CLASP1 degron

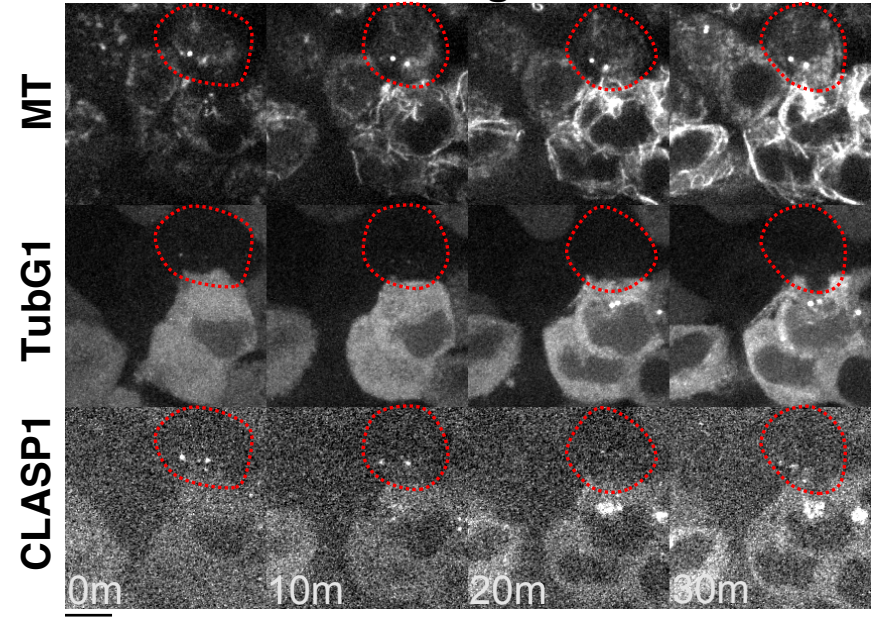

C TubG1 degron \& CAMSAP3KO \& CAMSAP1/2 RNAi

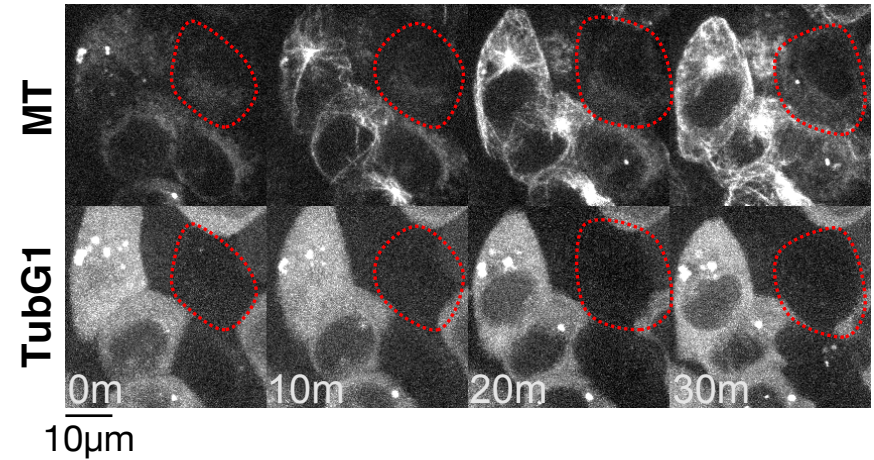

F MT appearance $\left(37^{\circ} \mathrm{C}\right)$

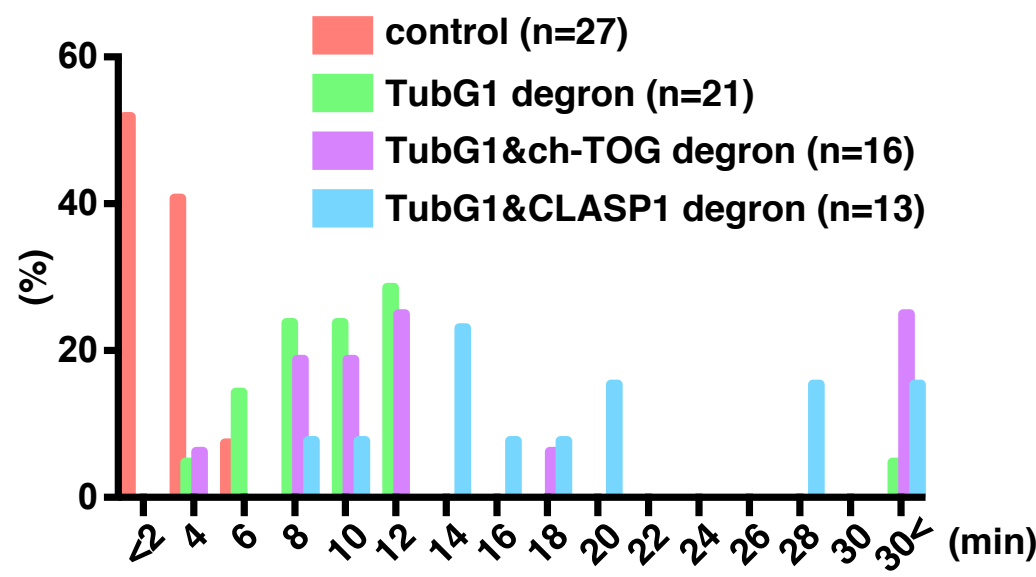

D Interphase double degron or KO

$$
\text { Regrowth No regrowth }
$$

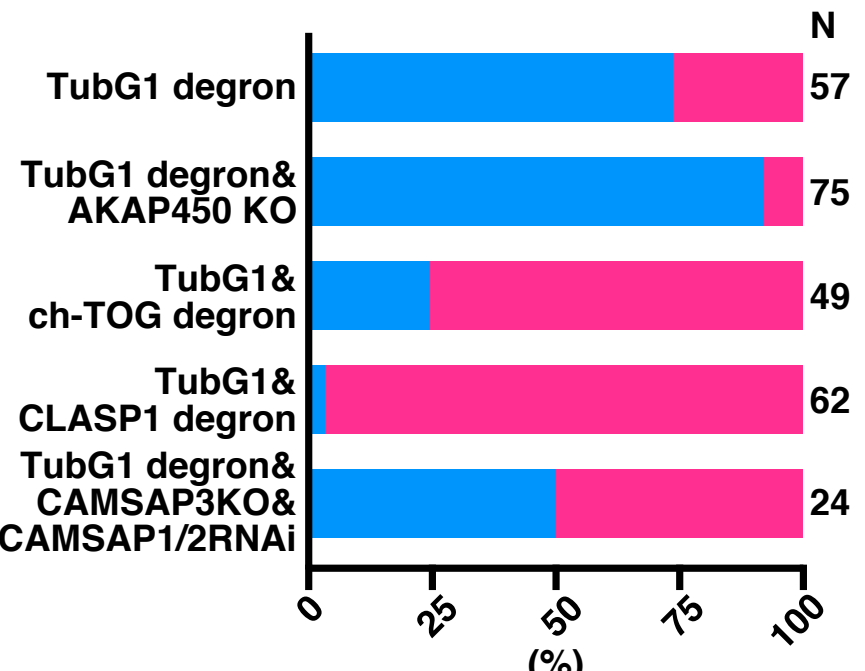

E

\section{SiR-tub signal in double degron cells}

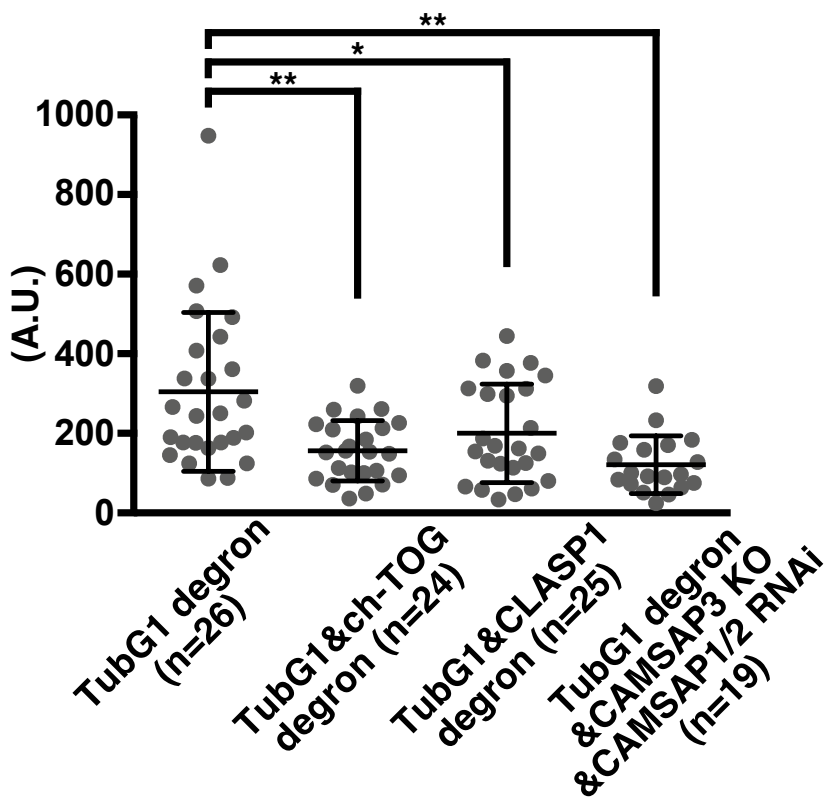


bioRxiv preprint doi: https://doi.org/10.1101/2021.08.13.456214; this version posted August 13,2021 . The copyright holder for this preprint

(which was not certified by peer review) is the author/funder, who has granted bioRxiv a license to display the preprint in perpetuity. It is made available under aCC-BY-NC 4.0 International license.

\section{Figure 6. CLASP1 promotes $\gamma$-tubulin-independent MT generation}

(A-C) Suppression of MT regrowth by double depletion of $\gamma$-tubulin and ch-TOG (A), CLASP1 (B), or CAMSAP1/2 (C, CAMSAP3 KO background) at $25^{\circ} \mathrm{C}$. Depleted cells are marked in red circles, whereas the surrounding cells with $\gamma$-tubulin and MAPs acted as the internal controls. Bars, $10 \mu \mathrm{m}$. (D, E) Frequency of MT appearance (D) and MT intensity (E) in the indicated lines $\left(25^{\circ} \mathrm{C}, 30 \mathrm{~min}\right.$ after nocodazole washout). $\mathrm{p}=0.0009,0.0313,<0.0001$ (one-way ANOVA, Tukey's multiple comparisons). (F) Time of MT apperance after nocodazole washout at $37^{\circ} \mathrm{C}$ in the indicated lines. 

made available under aCC-BY-NC 4.0 International license.

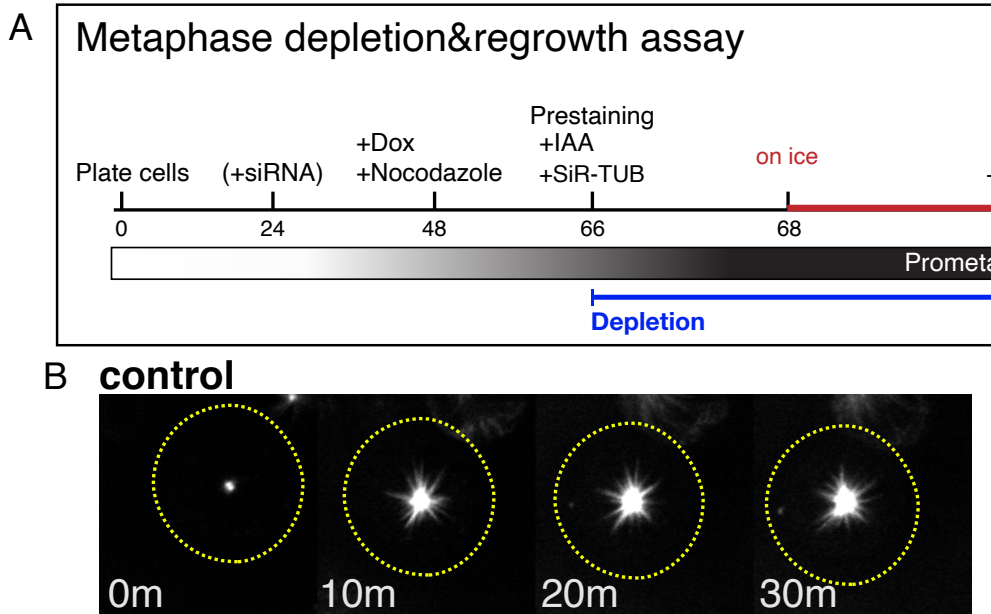

\section{TubG1 degron}

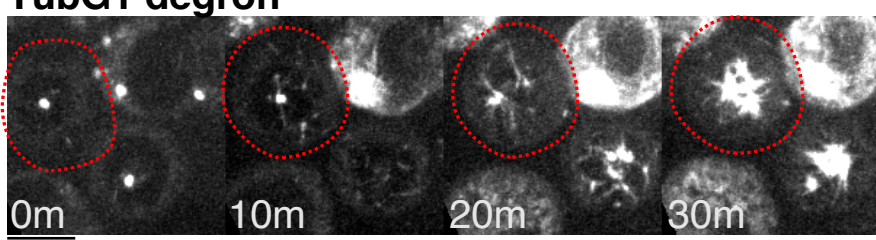

D TubG1\&ch-TOG degron

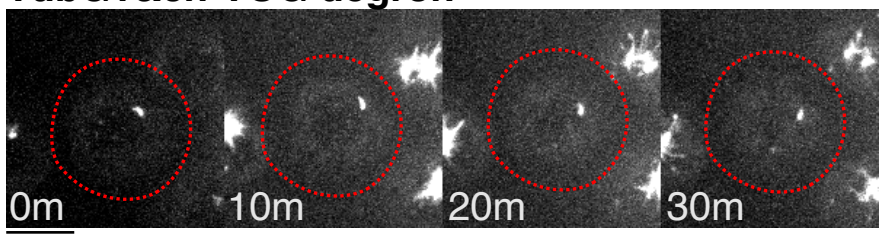

E TubG1\&CLASP1 degron

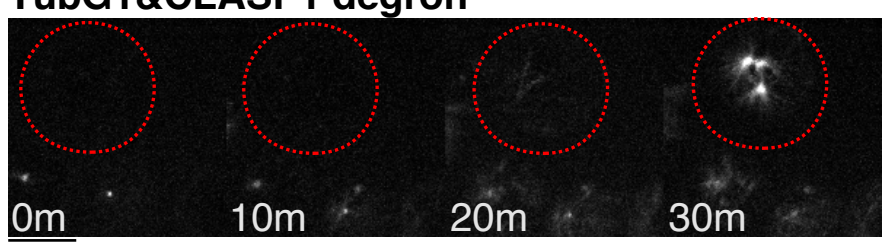

F TubG1\&TPX2 degron

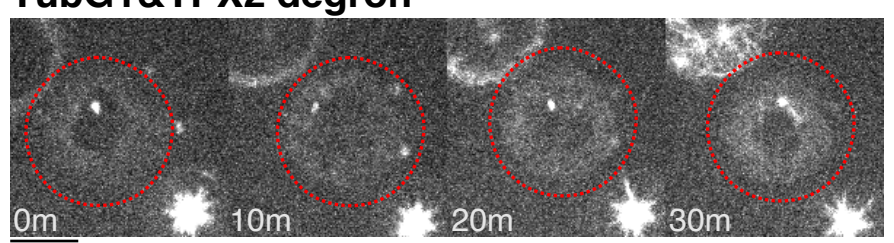

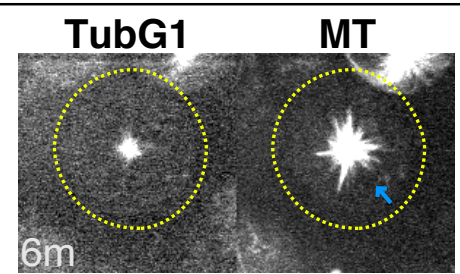

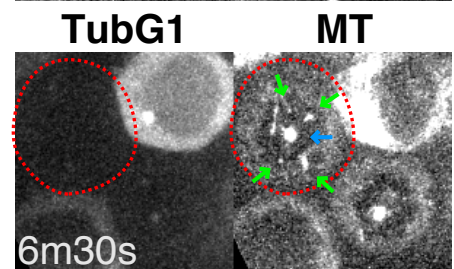

Wash Move to the

+IAA microscope + SiR-TUB stage
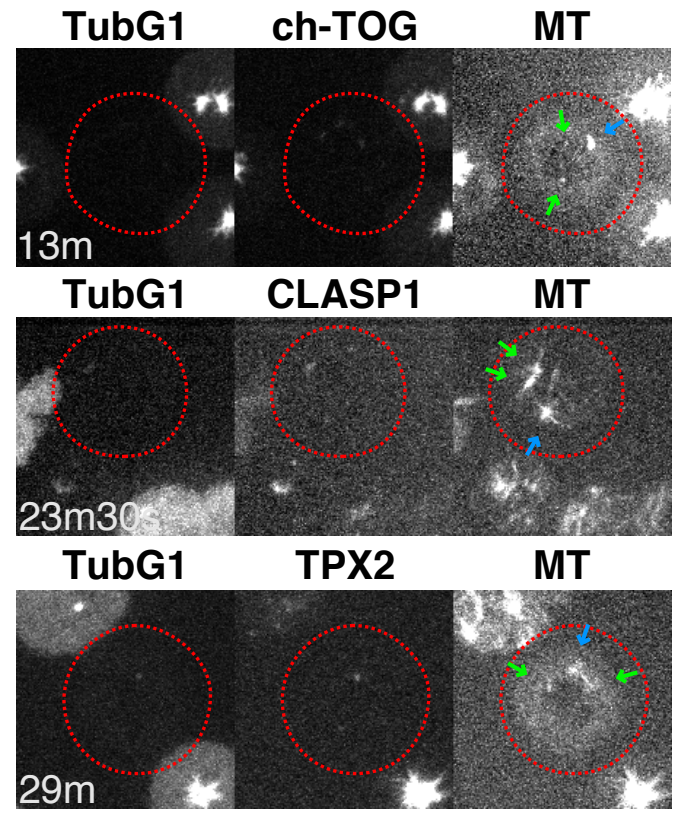

G

\section{de novo MTOC appearance}

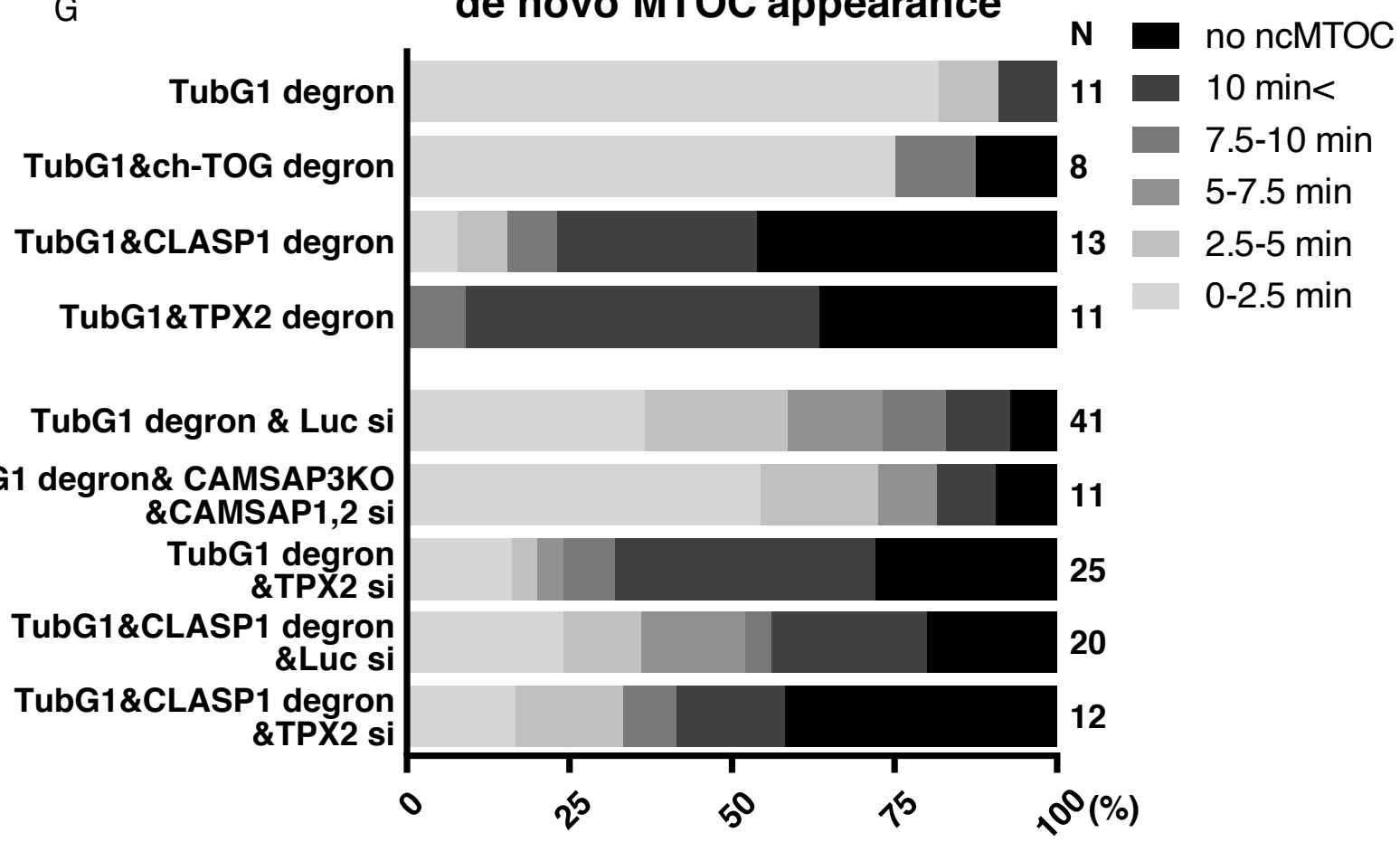


bioRxiv preprint doi: https://doi.org/10.1101/2021.08.13.456214; this version posted August 13,2021 . The copyright holder for this preprint

(which was not certified by peer review) is the author/funder, who has granted bioRxiv a license to display the preprint in perpetuity. It is made available under aCC-BY-NC 4.0 International license.

Figure 7. CLASP1 and TPX2 promote $\gamma$-tubulin-independent MTOC formation in mitosis

(A) Flowchart of MT regrowth assay in mitosis. (B-F) MT regrowth after drug washout in the indicated cell lines. The cells with undetectable levels of $\gamma$-tubulin and MAPs are marked in red circles, whereas the control cells are marked in yellow. Blue arrows on the right panel indicate the centriole, which retains MTs even after cold/drug treatment, whereas green arrows indicate ncMTOCs. Bars, $10 \mu \mathrm{m}$. (G) Timing of ncMTOC formation after nocodazole washout in the indicated cell lines. 
A

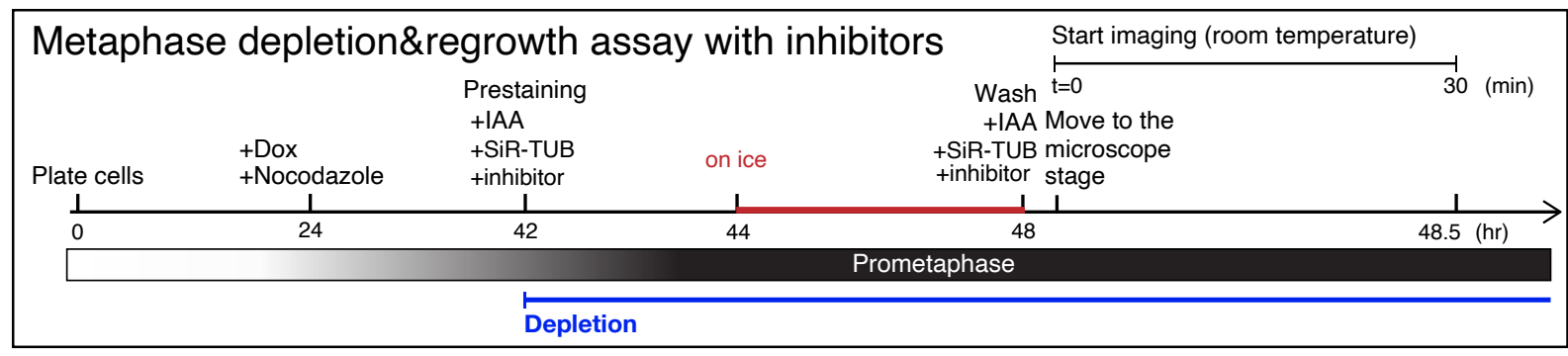

B TubG1 degron in DMSO

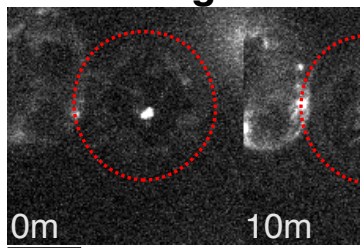

C TubG1 degron in 10 $\mu \mathrm{M} \mathrm{BI} 2536$

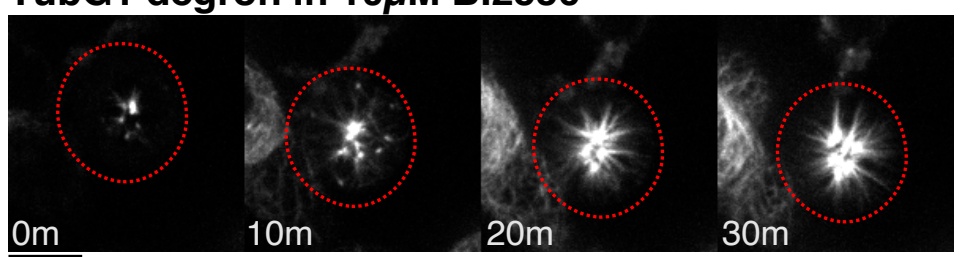

D TubG1 degron in 10 $\mu$ M ZM447439

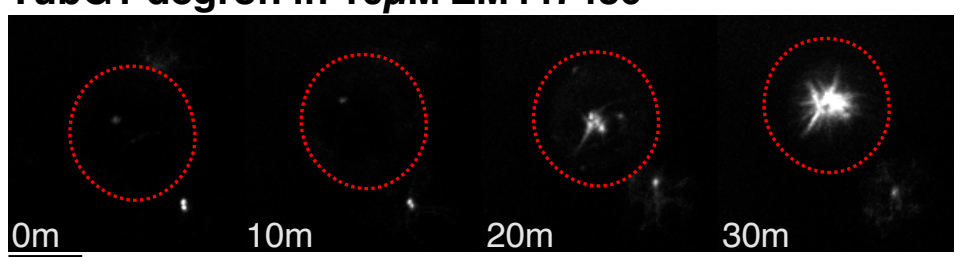

E TubG1 degron in $0.5 \mu \mathrm{M}$ Alisertib

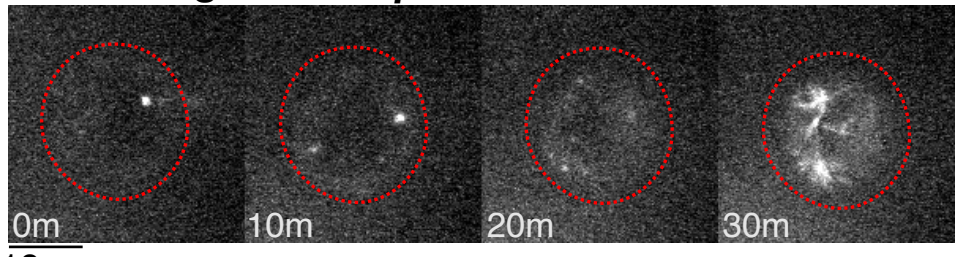

$\overline{10 \mu \mathrm{m}}$

\section{de novo MTOC appearance}

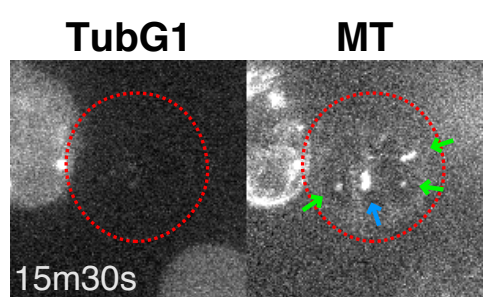

TubG1 MT

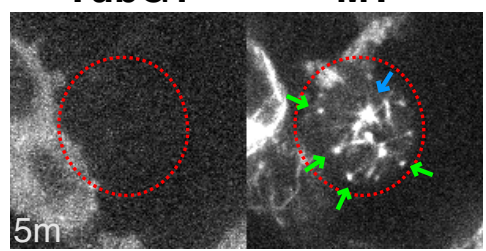

TubG1 MT
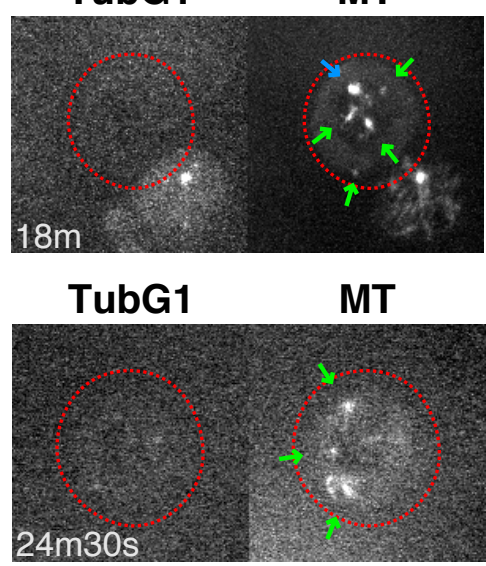

$\mathrm{F}$

$\mathbf{N}$

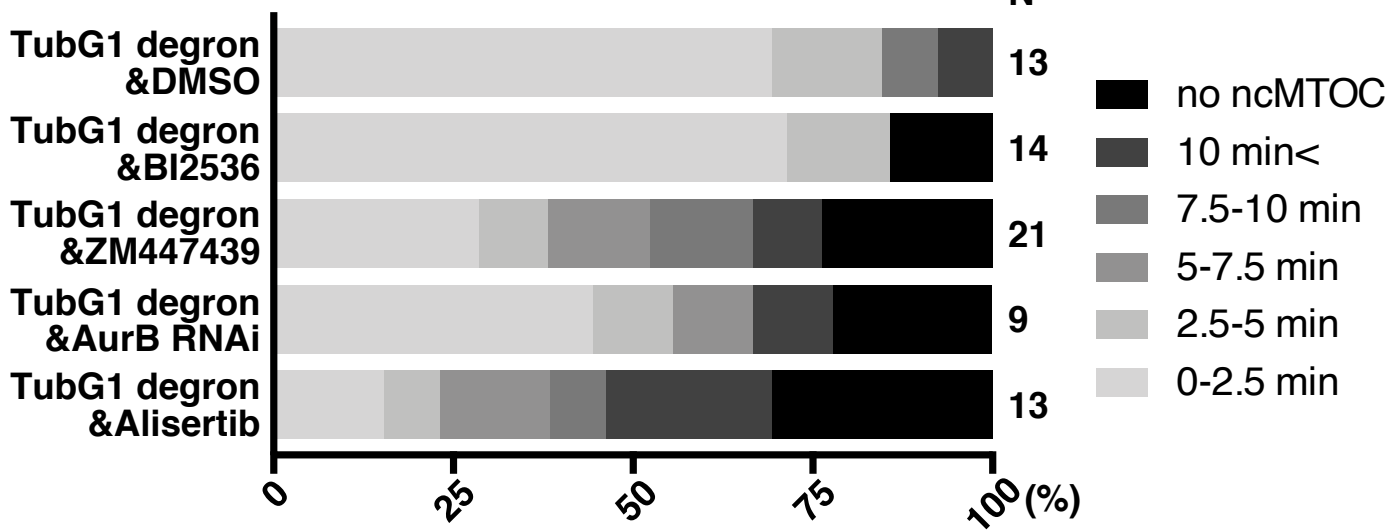

Figure 8. Aurora kinases contribute to $\gamma$-tubulin-independent MTOC formation in mitosis

(A) Flowchart of MT depolymerisation-regrowth assay in prometaphase combined with auxin-induced degron and drug treatment. (B-E) MT regrowth after drug washout in the indicated cell lines and treatment. The cells with undetectable levels of $\gamma$-tubulin are marked in red circles. Blue arrows on the right panel indicate the centriole, which retains MTs even after cold/drug treatment, whereas green arrows indicate non-centriolar MTOCs. Bars, $10 \mu \mathrm{m}$. (F) Timing of ncMTOC formation after nocodazole washout in the indicated cell treatment. 
bioRxiv preprint doi: https://doi.org/10.1101/2021.08.13.456214; this version posted August 13, 2021. The copyright holder for this preprint

(which was not certified by peer review) is the author/funder, who has granted bioRxiv a license to display the preprint in perpetuity. It is made available under aCC-BY-NC 4.0 International license.

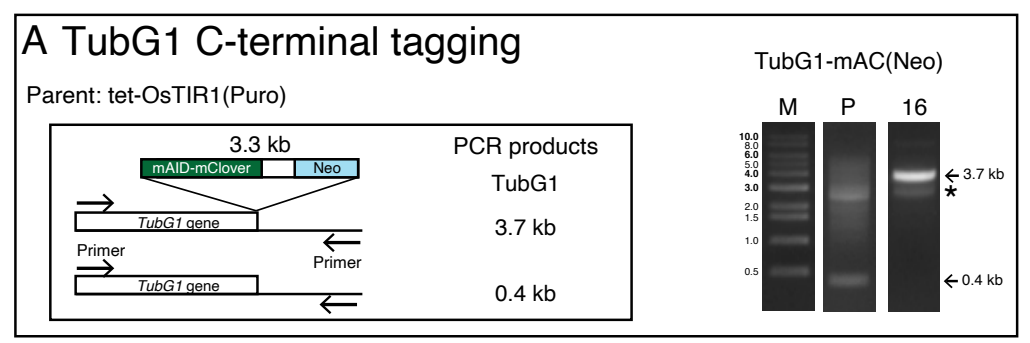

B TubG2 knock out Parent: tet-OsTIR1(puro) +TubG1-mAC(Neo)

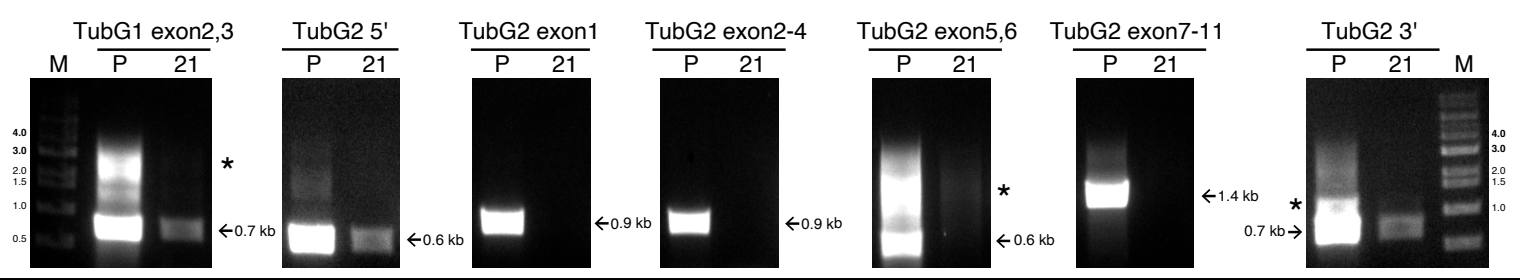

C ch-TOG C-terminal tagging

Parent: tet-OsTIR1(Puro)+TubG1-mAC (Neo)+TubG2 KO (BSD)

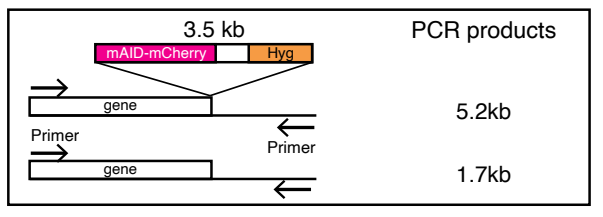

A: TubG1-mAC+TubG2 KO C: TubG1-mAC+TubG2 KO+ch-TOG-mACh B: ch-TOG-mACh $\quad$ D: TubG1-mAC+TubG2 KO+ch-TOG-mCh

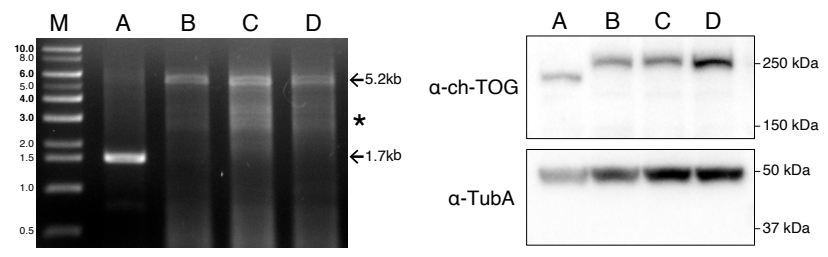

\section{CLASP1 C-terminal tagging}

Parent: tet-OsTIR1(Puro)+TubG1-mAC (Neo)+TubG2 KO (BSD)

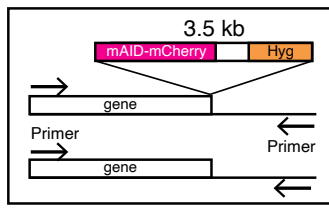

PCR products

$5.3 \mathrm{~kb}$

$1.8 \mathrm{~kb}$
A: TubG1-mAC+TubG2 KO C: TubG1-mAC+TubG2 KO+CLASP1-mACh B: CLASP1-mACh

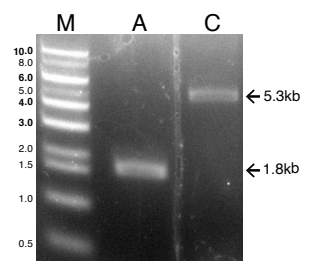

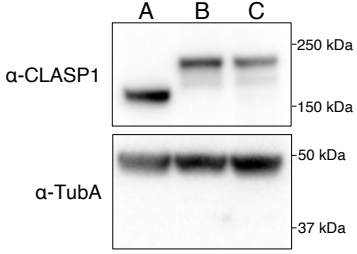

\section{E TPX2 N-terminal tagging}

Parent: tet-OsTIR1(Puro)+TubG1-mAC (Neo)+TubG2 KO (BSD)

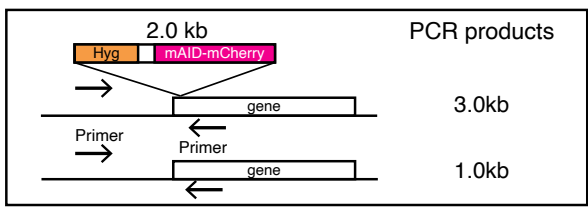

A: TubG1-mAC+TubG2 KO C: TubG1-mAC+TubG2 KO+TPX2-mAC B: TPX2-mACh
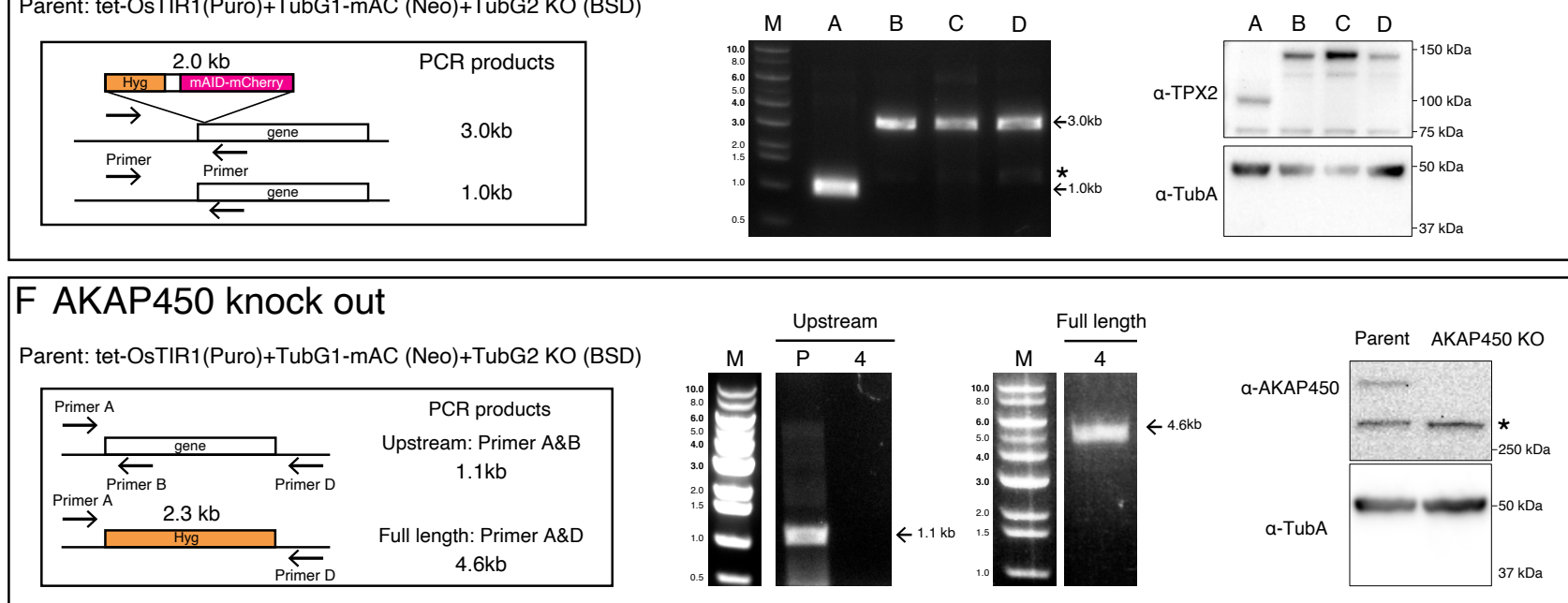

\section{G CAMSAP3 knock out}

Parent: tet-OsTIR1(Puro)+TubG1-mAC (Neo)+TubG2 KO (BSD)
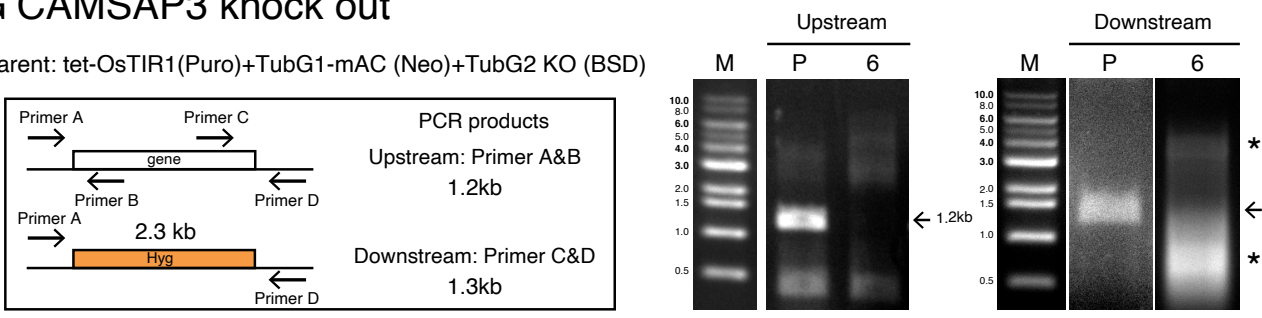

Parent CAMSAP3 KO 
bioRxiv preprint doi: https://doi.org/10.1101/2021.08.13.456214; this version posted August 13,2021 . The copyright holder for this preprint (which was not certified by peer review) is the author/funder, who has granted bioRxiv a license to display the preprint in perpetuity. It is made available under aCC-BY-NC 4.0 International license.

\section{Figure S1. Construction and confirmation of the cell lines used in this study}

Gene targeting strategy, PCR strategy, PCR results, and immunoblotting results are shown for the cell lines used in this study. 'P' marks at the top of the panels represent parental lines, whereas the numbers (e.g. '4', '16') indicate the line identification numbers. Asterisks indicate non-specific bands. (A) mAID-mClover ('mAC') tagging to TubG1. PCR amplified a 3.7-kb fragment in the tagged line. Immunoblotting results are shown in Fig. 1A. (B) Confirmation of TubG2 KO by PCR The lack of bands derived from exons was confirmed in the KO line. The TubG1 exon and TubG2 UTR regions were amplified as positive controls. (C) mAID-mCherry ('mACh') or mCherry ('mCh') tagging to chTOG. PCR amplified a 5.2-kb fragment in the tagged line. Immunoblotting results are shown on the right; the band is shifted upwards with the tag. (D) mAID-mCherry ('mACh') tagging to CLASP1. PCR amplified a 5.3-kb fragment in the tagged line. Immunoblotting results are shown on the right; the band is shifted upwards with the tag. (E) mAID-mCherry ('mACh') or mCherry ('mCh') tagging to TPX2. PCR amplified a 3.0-kb fragment in the tagged line. Immunoblotting results are shown on the right; the band is shifted upwards with the tag. (F) PCR and immunoblotting confirmation of AKAP450 KO cells. DNA amplification was not observed when a primer targeting an exon was used for the KO line, whereas the hygromycin cassette was amplified with the primers designed at UTRs (this primer set did not amplify very long AKAP450 genes in the parental line). Immunoblotting showed a specific $>250 \mathrm{kD}$ band only in the parental line. (G) PCR and immunoblotting confirmation of CAMSAP3 KO. DNA amplification was not observed when a primer targeting an exon was used for the KO line. Immunoblotting showed a specific $\sim 150 \mathrm{kD}$ band only in the parental line. 
A Spindle formation st $25^{\circ} \mathrm{C}$
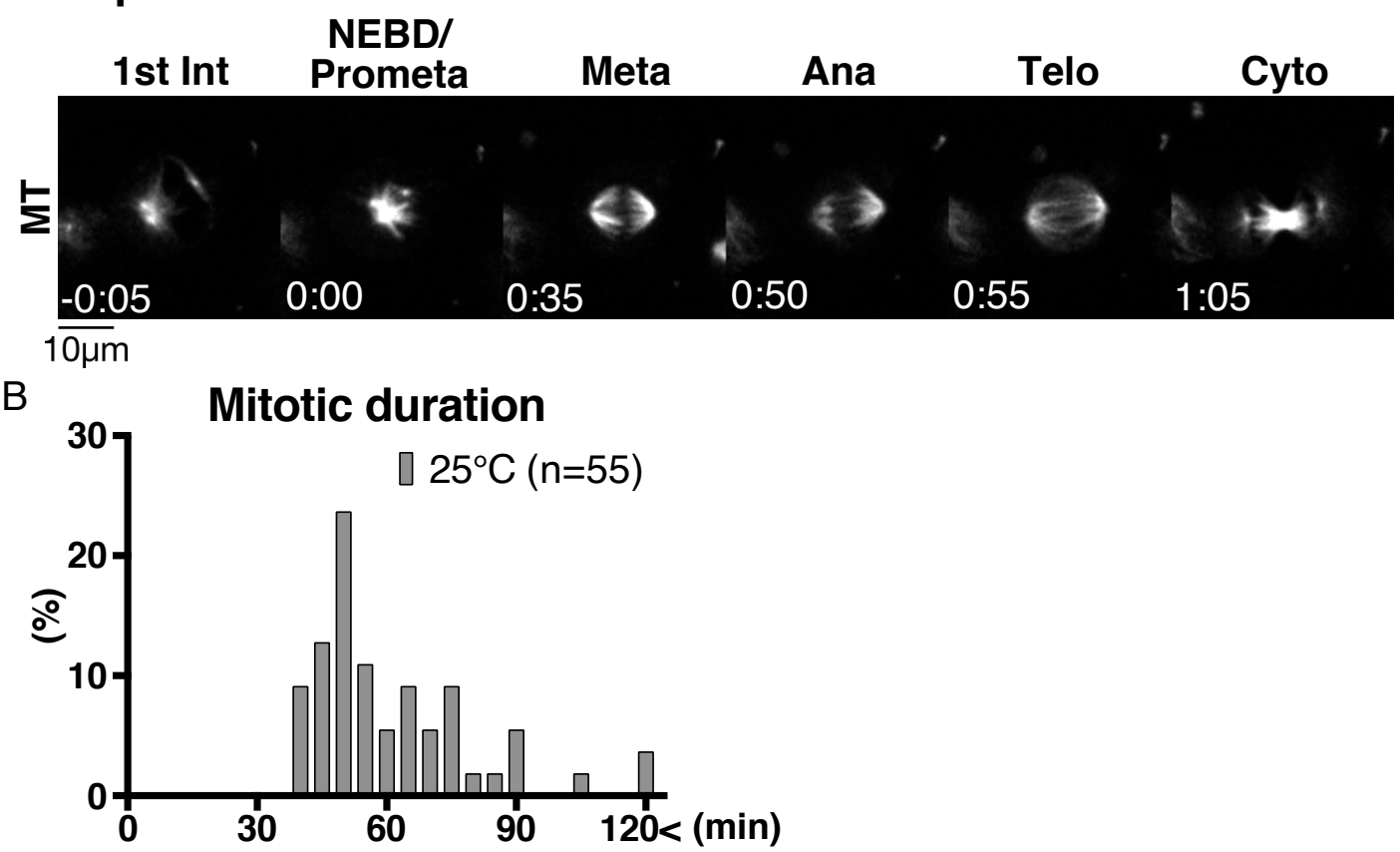

C TubG1-mAC + ch-TOG-mCh
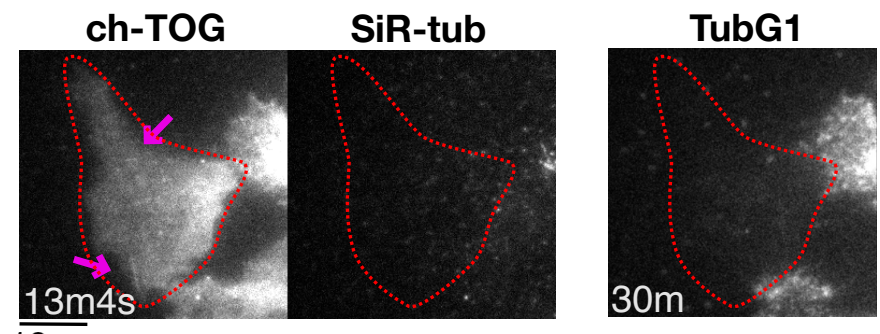

$\overline{10 \mu \mathrm{m}}$

\section{Magnified ch-TOG}

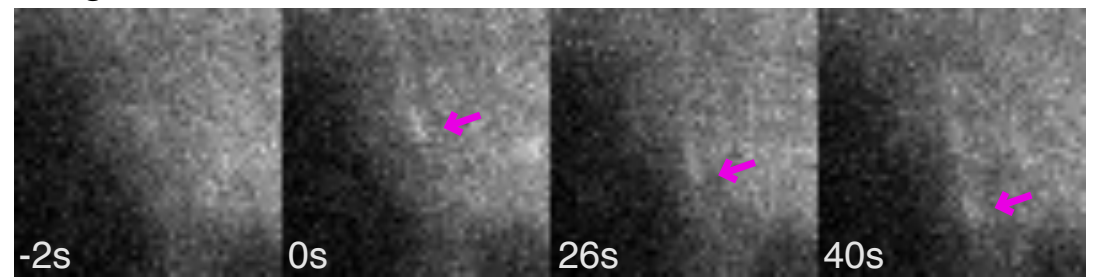

$\overline{1 \mu \mathrm{m}}$

\section{D}

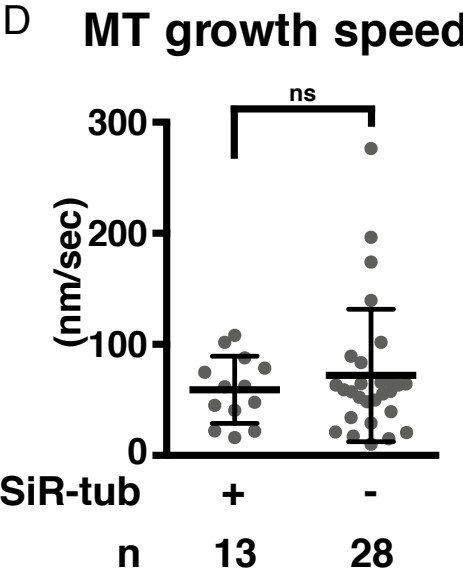

E MT appearance

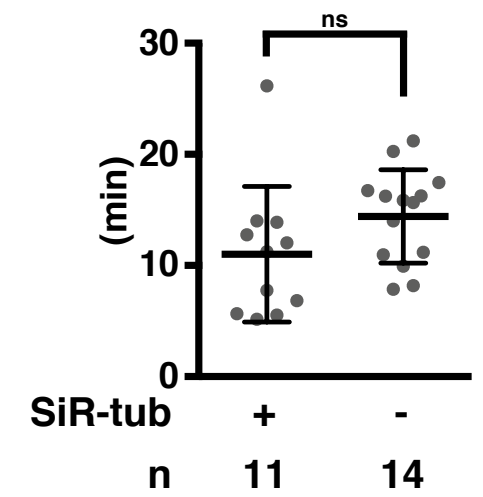

Figure S2. Validation of MT regrowth assay

(A) Mitosis of HCT116 cell line at $25{ }^{\circ} \mathrm{C}$. Time 0 corresponds to NEBD. (B) Mitotic duration at $25{ }^{\circ} \mathrm{C}$ (NEBD to anaphase onset). (C) MT nucleation in the absence of $\gamma$-tubulin, without SiR-tubulin staining, in interphase. The cells with undetectable levels of $\gamma$-tubulin are marked in red circles. MTs were visualised using ch-TOG-mCherry (arrows). (D, E) MT dynamics of $\gamma$-tubulin-depleted cells based on ch-TOG-mCherry signals with or without SiR-tubulin staining. MT growth rate was determined based on kymographs of ch-TOG-mCherry. Statistical evaluation was performed using unpaired t-test with Welch's correction $(\mathrm{p}=0.3644,0.1315)$. 
A TubG1 degron \& AKAP450 KO

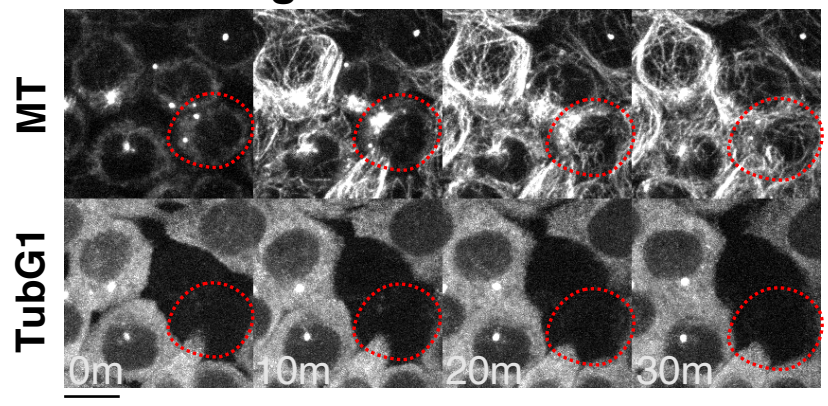

B TubG1 degron \& CAMSAP3 KO

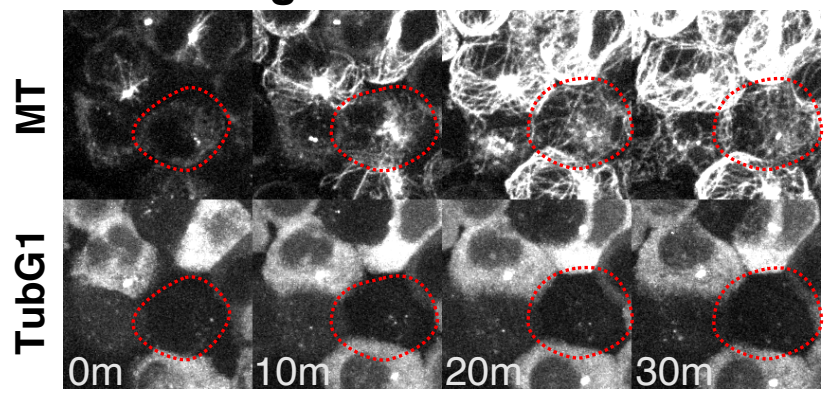

$\overline{10 \mu \mathrm{m}}$

C Regrowth frequency

Regrowth No regrowth

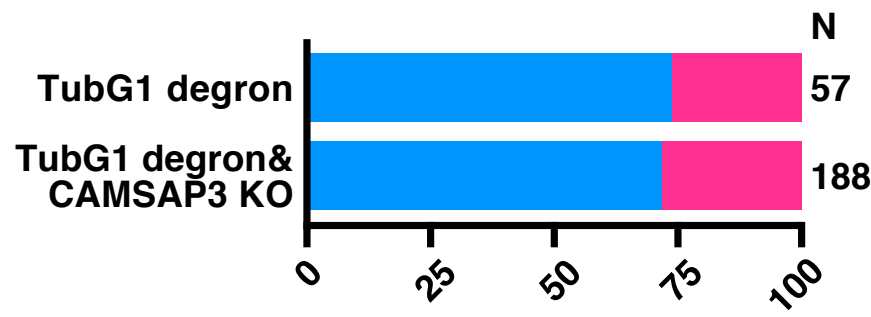

(\%)

\section{TubG1 degron \& CAMSAP3 KO \& Luc RNAi}

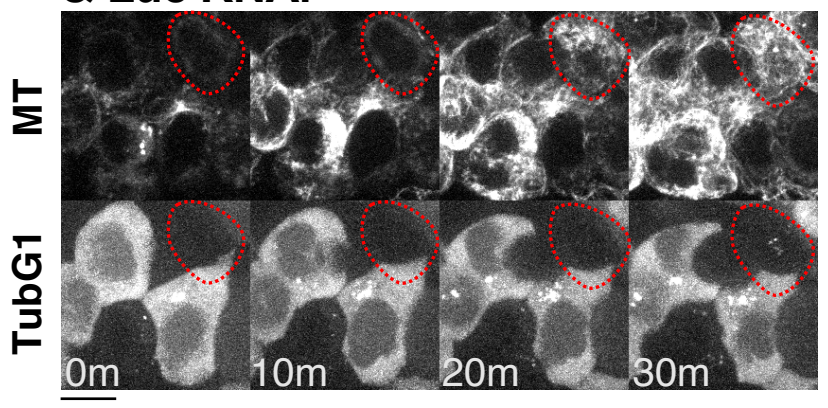

E TubG1 degron \& CAMSAP3 KO \& CAMSAP1 RNAi

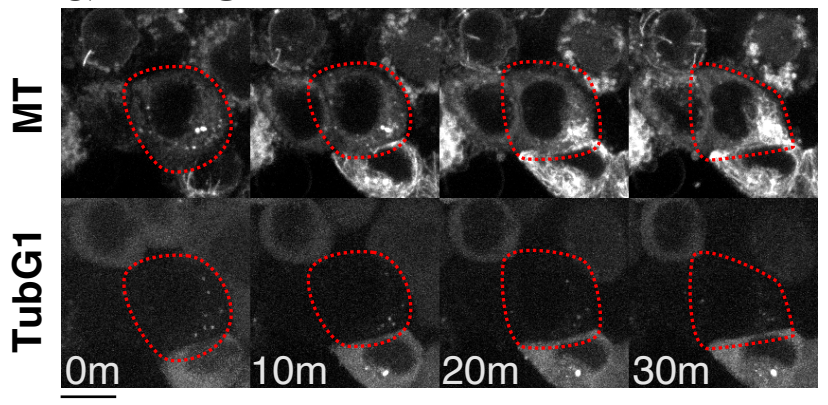

F TubG1 degron \& CAMSAP3 KO \& CAMSAP2 RNAi

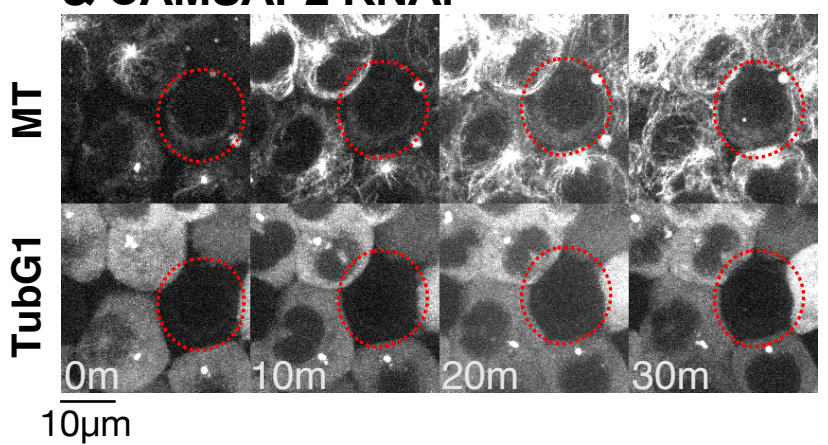

G Regrowth frequency

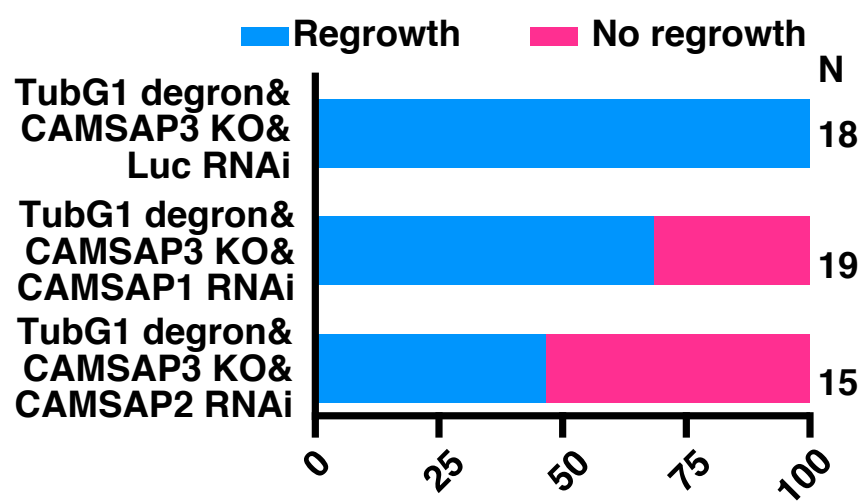

(\%)

Figure S3. Additional data on MT regrowth ability in interphase cells

(A-B, D-F) MT regrowth in various lines. The cells marked in red circles show no detectable $\gamma-$ tubulin signals. (C, G) Frequency of MT regrowth. MT appearance was assessed 30 min after nocodazole washout. The TubG1 degron data in (C) are the duplicates of Fig. 6D. 
bioRxiv preprint doi: https://doi.org/10.1101/2021.08.13.456214; this version posted August 13, 2021. The copyright holder for this preprint

(which was not certified by peer review) is the author/funder, who has granted bioRxiv a license to display the preprint in perpetuity. It is made available under aCC-BY-NC 4.0 International license.

A TubG1-mAC + ch-TOG-mCh TubG1 ch-TOG MT

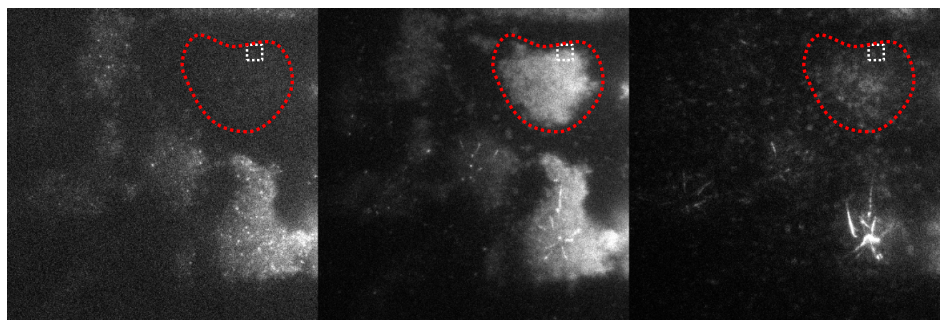

\section{$30 \mu \mathrm{m}$}

B

ㄴ.

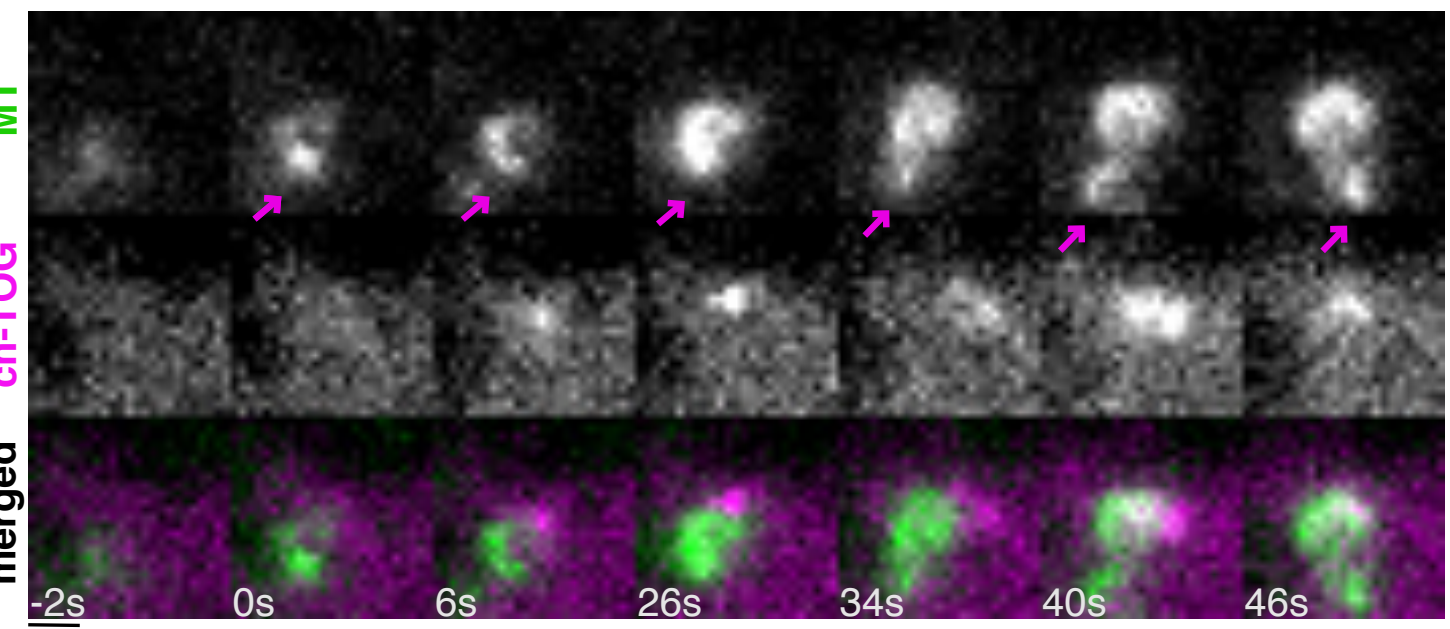

$\overline{1 \mu \mathrm{m}}$

C TubG1-mAC + CLASP1-mCh

TubG1 CLASP1

MT
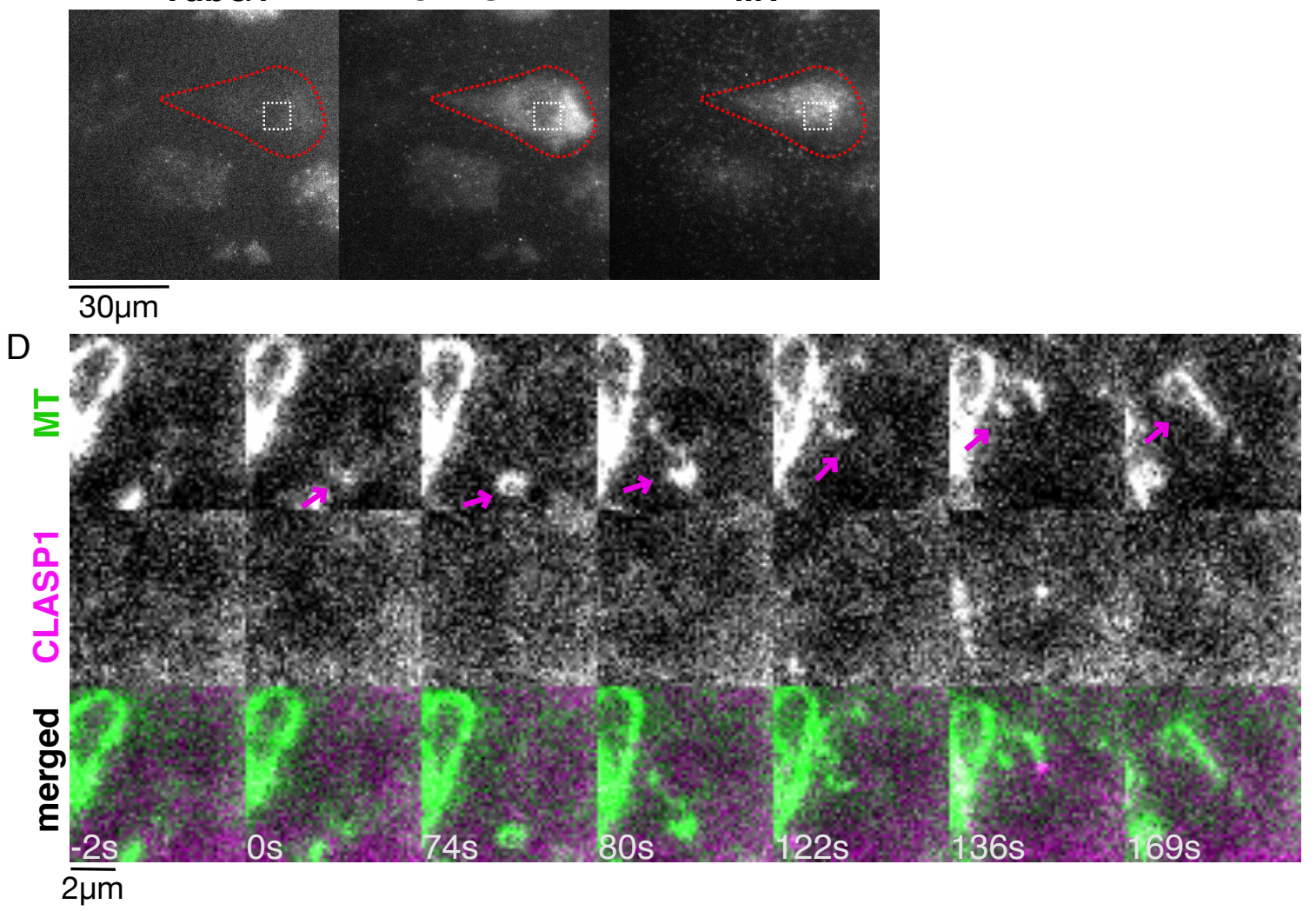

Figure S4. ch-TOG and CLASP1 localisation during $\gamma$-tubulin-independent MT nucleation in the interphase cytoplasm

Oblique illumination fluorescence microscopy of TubG1-mAID-mClover, ch-TOG-mCherry (or CLASP1-mCherry), and SiR-tubulin. Three-colour images were acquired to show $\gamma$-tubulin depletion in the first frame $(\mathrm{A}, \mathrm{C})$, followed by two-colour imaging every $2 \mathrm{~s}(\mathrm{~B}, \mathrm{D})$. A part of the cytoplasm (boxed in A, C) is magnified to show a nucleation event (B, D). Cells marked in red circles showed no detectable $\gamma$-tubulin signals. 


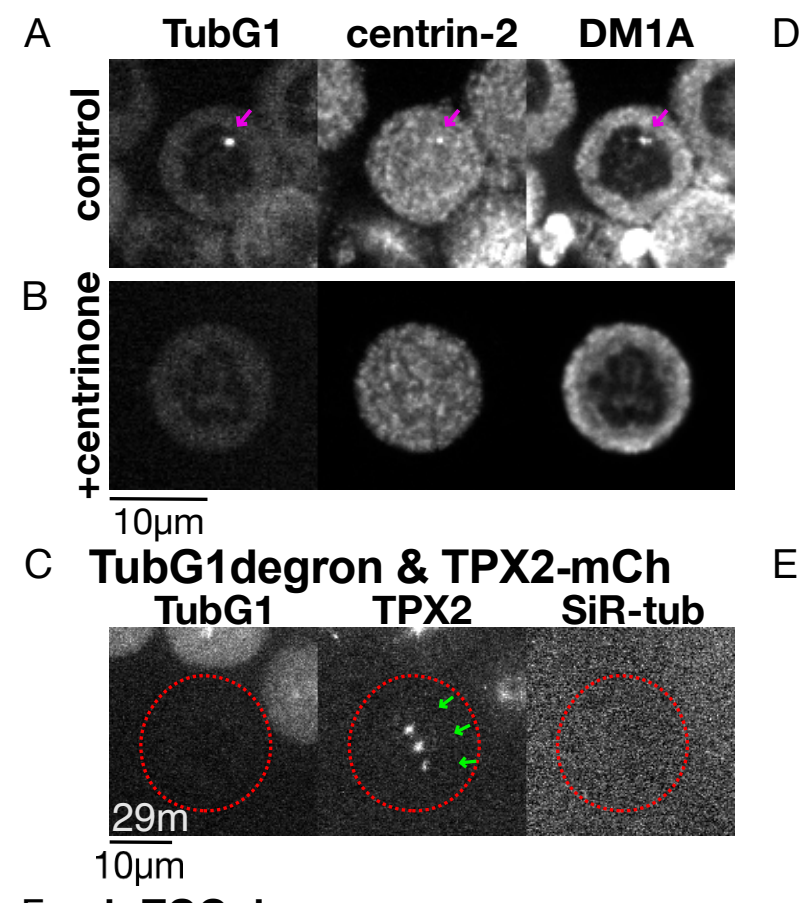

F ch-TOG degron

Non-centriolar MTOC appearance

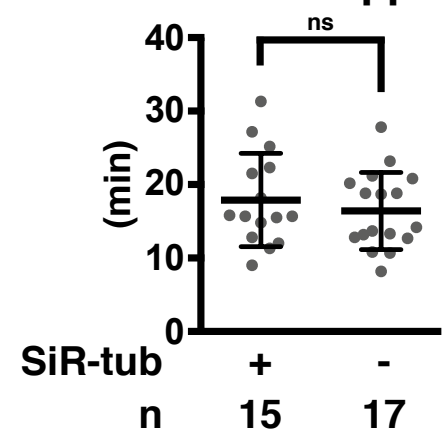

E MTOC number
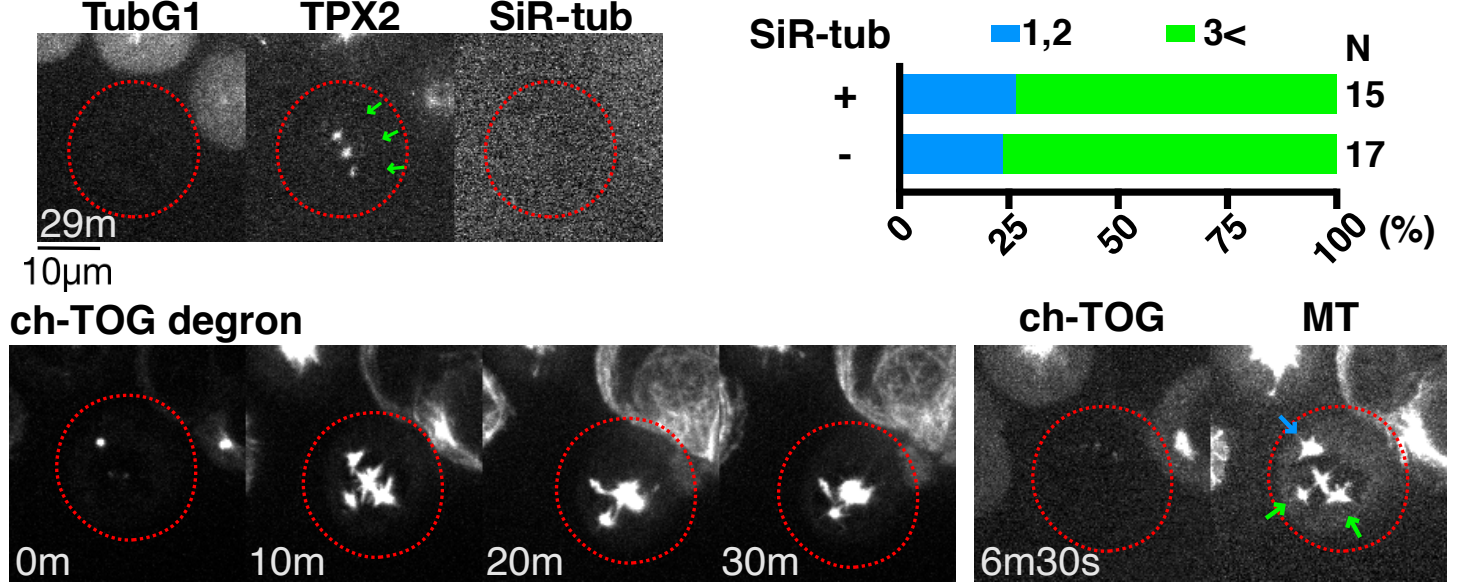

G CLASP1 degron

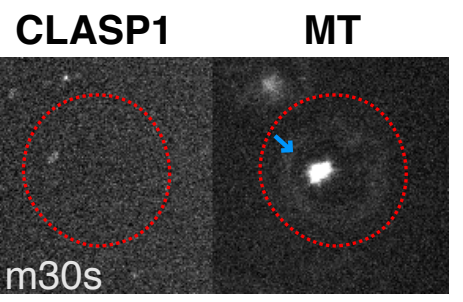

H TPX2 degron

TPX2

MT
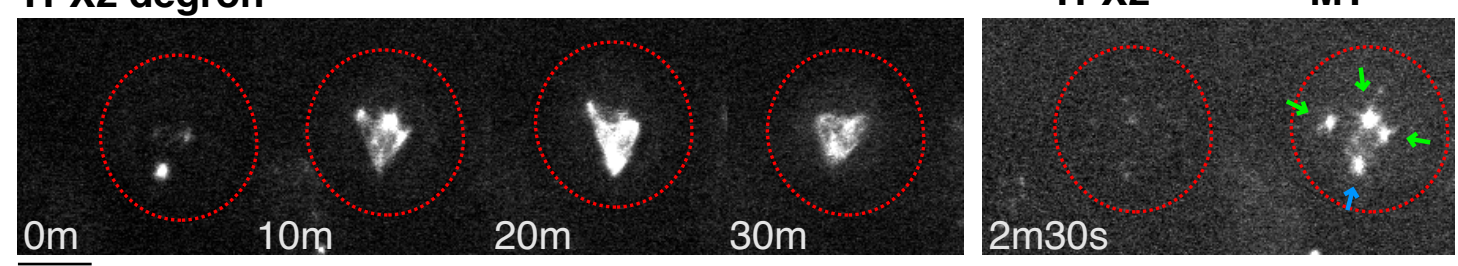

$\overline{10 \mu \mathrm{m}} \quad$ I MTOC number

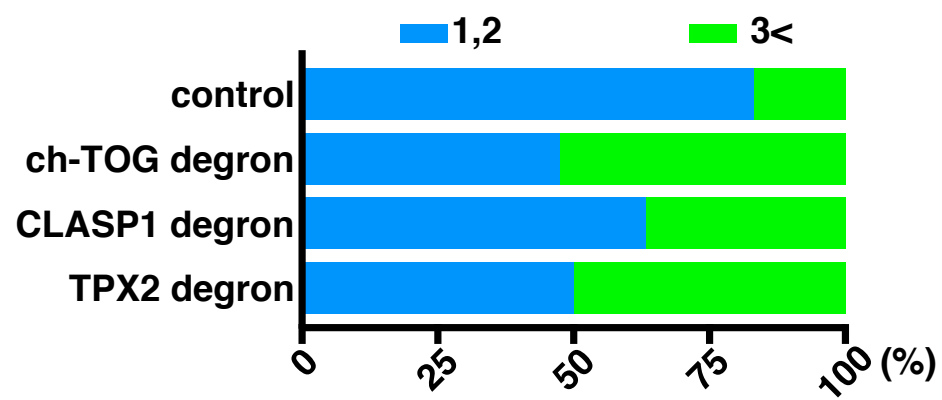

$J$ Regrowth frequency

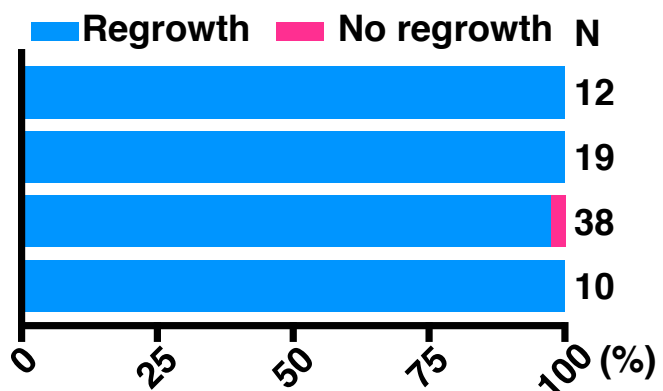


bioRxiv preprint doi: https://doi.org/10.1101/2021.08.13.456214; this version posted August 13,2021 . The copyright holder for this preprint

(which was not certified by peer review) is the author/funder, who has granted bioRxiv a license to display the preprint in perpetuity. It is made available under aCC-BY-NC 4.0 International license.

\section{Figure S5. Additional data on MTOC formation and MT regrowth in mitosis}

(A, B) Centriolar MTs remain even after rigorous MT depolymerisation with nocodazole (arrows). (C) MTOC formation in the absence of $\gamma$-tubulin, with or without SiR-tubulin in mitosis. The cells with undetectable levels of $\gamma$-tubulin are marked in red circles. Green arrows indicate non-centriolar MTOCs. TPX2-mCherry was used to visualise MTs. (D) The time of new MTOC appearance after nocodazole washout in the absence of $\gamma$-tubulin with or without SiR-tubulin staining (18 $\pm 6 \mathrm{~min}, 16 \pm$ 5 min, $p=0.483$ (unpaired t-test with Welch's correction)). (E) Total MTOC numbers did not change with or without SiR-tubulin staining. (F-H) MT regrowth after ch-TOG, CLASP1, or TPX2 degron treatment. Red circles indicate the cells with undetectable levels of proteins. Note that $\gamma$-tubulin is intact in these lines. Bars, $10 \mu \mathrm{m}$. (I, J) Total MTOC numbers per cell and the frequency of cells with MTs at 30 min after nocodazole washout. 